\title{
The influence of congruency proportion, target eccentricity, and valence strength on the spatial-valence metaphoric congruency effect in a word valence judgment task
}

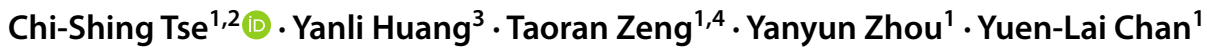

Received: 3 November 2019 / Accepted: 14 September 2020 / Published online: 6 October 2020

(c) Springer-Verlag GmbH Germany, part of Springer Nature 2020

\begin{abstract}
In a word valence judgment task, positive words (e.g., excellence) are judged faster when presented at the top (congruent position) than at the bottom of the screen (incongruent position), whereas the opposite pattern occurs for negative words (e.g., disaster). This spatial-valence metaphoric congruency effect reflects top-positive/bottom-negative metaphoric association and may be attributed to at least three possible mechanisms: spreading activation between spatial and valence concepts (activation account), epistemic function that a conceptual metaphor serves to reduce the uncertainty associated with valence concepts (epistemic account), and/or the extent to which spatial-valence metaphoric association is relevant to task demand (relevance account). In three experiments, we manipulated congruency proportion, target eccentricity, and valence strength in a word valence judgment task to test these three possible accounts. Results showed that the metaphoric congruency effect was larger when a high (vs. equal) proportion of targets appears in congruent, relative to incongruent, position, and for targets with strong (vs. weak) valence. However, the effect in reaction time measure was not modulated by whether the target appeared in the position being near vs. far away from the center of the screen. The overall findings are better accommodated by the relevance account. The implications of the current findings on other theoretical accounts, such as Conceptual Metaphor Theory and polarity correspondence account, are also discussed.
\end{abstract}

\section{Introduction}

\section{Conceptual metaphor}

According to the Conceptual Metaphor Theory (e.g., Lakoff \& Johnson 1999; Meier, Schnall, Schwarz, \& Bargh 2012; Santiago, Roman, \& Ouellet 2011), a conceptual metaphor is a linguistic expression as well as a cognitive tool that helps individuals to comprehend abstract concept (target) through

Chi-Shing Tse

cstse@cuhk.edu.hk

1 Department of Educational Psychology, The Chinese University of Hong Kong, New Territories, Hong Kong, China

2 Centre for Learning Sciences and Technologies, The Chinese University of Hong Kong, Hong Kong, China

3 School of Psychology, Nanjing Normal University, Nanjing, China

4 Department of Sports Science and Physical Education, The Chinese University of Hong Kong, Hong Kong, China congruent concrete concept (source) via a metaphoric association. People cannot enjoy the same direct experience of interacting with abstract concepts that do not have physical referents in the world as they can with concrete concepts. The spatial-valence metaphoric association, the focus of the current study, offers a good example. Image schemas are conceptual structures that represent perceptual relation (spatial position) via sensorimotor action (movement in space). The access to valence via the metaphoric association can activate the image schema of space because valence can be grounded through sensorimotor experience (e.g., people stand tall when they feel proud but have slouched posture when they feel depressed, e.g., Tracy \& Matsumoto 2008) and/or everyday language use (e.g., people may use a spatial position to express their affect, e.g., "I am feeling down" when they are in a sad mood).

The spatial-valence metaphoric association has been supported by empirical studies. Wapner et al. (1957) found that after receiving positive (or negative) feedback for performance, participants showed an upward (or downward) shift when bisecting a luminous square. Meier and Robinson (2004; see also Huang \& Tse 2015) reported that valence 
judgments are faster and/or more accurate when the target appears in a metaphorically congruent spatial position (a positive word at the top of the screen and a negative word at the bottom of the screen) than in a metaphorically incongruent spatial position (a positive word at the bottom and a negative word at the top). This metaphoric congruency effect refers to a facilitation of congruent concrete concepts, relative to incongruent ones, in processing abstract concepts. Crawford et al. (2006) showed that the location of positive (or negative) stimuli was better recalled when they were presented at the top (or bottom) position on the screen in the study phase (see also Palma et al. 2011, 2014). Weger et al. (2007) found that participants rated higher (or lower) in tone discrimination after judging the valence of a positive (or negative) word. Similar congruency effects have been reported for other conceptual metaphors, such as brightness-valence (Huang, Tse, \& Xie 2018; Meier et al. 2004, 2015). In the current study, a spatial-valence metaphoric congruency effect is said to occur when participants are faster and/or more accurate to judge a target's word valence when its position and valence are congruent (top-positive/ bottom-negative) than when they are not (top-negative/ bottom-positive).

\section{The activation, epistemic, and relevance accounts of metaphoric congruency effect}

Three possible accounts could be proposed to explain the spatial-valence metaphoric congruency effect. The current study was designed to test the predictions derived from these accounts. First, the effect could be attributed to the spreading activation in a "metaphor" network, analogous to the spreading activation in a semantic network that accounts for semantic priming effect (e.g., Collins \& Loftus 1975; Neely 1991; Posner \& Snyder 1975; Voss, Rothermund, Gast, \& Wentura 2013). The activation of spatial concept, as driven by one's sensory experience in the physical world, may spread to the metaphorically associated target concept, including valence, and this in turn facilitates the valence judgment (e.g., Meier et al. 2012). The metaphoric association is acquired via repeated exposure of source concepts (space) and target concepts (valence, e.g., Williams et al. 2009). Some have argued that the source concept is used to structure the target concept during ontogenetic development, such that it becomes part of the representation of the latter (e.g., Lakoff \& Johnson 1980, 1999; Mandler 1992). This latter view postulates that valence is mentally represented as a vertical spatial representation. According to this activation account, the magnitude of a metaphoric congruency effect depends on the strength of the metaphoric association. The stronger the target's word valence (or the more extreme the target's word position), the more likely the target may receive activation spread from its spatial information, the faster the valence judgments would be made on that target word, and in turn, the larger the metaphoric congruency effect would occur.

Second, the metaphoric congruency effect could be modulated by the extent to which the metaphoric association is relevant to task demand. The spatial-valence metaphoric congruency effect did not occur when participants' attention was not directed to the relevant (spatial or valence) domain (e.g., Santiago, Ouellet, Roman, \& Valenzuela 2012; see also Santiago et al. 2011). de la Vega et al. (2012; see also Dudschig et al. 2015) obtained the effect of metaphoric association between horizontal space (left/right) and word valence (negative/positive) in a task with explicit response mapping between valence and response side (e.g., judging the word valence by pressing a key on the left or right side of a keyboard). However, the effect did not occur in a lexical decision task in which word valence was not relevant to the task demand (judging whether a word is correctly spelled). Flumini and Santiago (2013; see also Lebois et al. 2015) showed that the left-past/right-future space-time metaphoric association of a time-related word was activated only when participants made a temporal judgment (does the word refer to the past or future meaning?), but not when they made a lexical decision (is the word correctly spelled?). Huang, Tse, and Cho (2014) reported that the effect of metaphoric association between valence (positive/negative) and cardinal direction (north/south) could be modulated by respective cultural experience of participants from Hong Kong and New York (see also Klein et al. 2018, for a large-scale replication of this finding). By having participants perform the typical word valence judgment task (Meier \& Robinson 2004) with or without the demand of performing a secondary task (i.e., rehearsing six sequentially presented digits in correct order) as a working memory load, Huang and Tse (2015) investigated whether the activation of spatial-valence metaphoric association was automatic. They found that the spatial-tovalence metaphoric congruency effect occurred only when there was no working memory load and interpreted their results as evidence against the automatic activation of spatial-valence metaphoric association. However, their results could also be explained by this relevance account. When a word valence judgment task was combined with the secondary task, the demand for concurrently performing both tasks might reduce the relevance of spatial-valence metaphoric association in tackling the overall task. Thus, participants might rely less on the spatial-valence metaphoric association in making responses and produce a null metaphoric congruency effect. According to the relevance account, the magnitude of the metaphoric congruency effect depends on the extent to which the metaphoric association could facilitate participants to respond in the task context. In the present study, we manipulated congruency proportion and valence strength to test this relevance account. When participants are 
informed about the high (vs. equal) proportion of congruent trials in the task, they might be more aware of the benefit of following the spatial-valence metaphoric association to respond, and in turn, they would show a larger metaphoric congruency effect. Targets with stronger valence may also hint participants to respond in accord to spatial-valence metaphoric association, such that they would yield larger metaphoric congruency effect.

Third, some researchers (e.g., Keefer, Landau, Sullivan, \& Rothschild 2011; Landau, Meier, \& Keefer 2010) have proposed that conceptual metaphors serve an epistemic function, which is similar to certainty motivation in the theory of lay epistemology (Kruglanski 1989). The metaphoric association between a concrete concept and an abstract concept may provide a subjective sense of certainty about the abstract concept, so individuals can use this association to reduce the uncertainty arisen when processing abstract targets. The metaphoric association is more likely used to interpret the target-relevant information when target uncertainty is high. This epistemic account has only been tested in a few social perception studies. Keefer et al. (2011) tested how situational variability in uncertainty could moderate the spatial-valence metaphoric congruency effect. They argued that when uncertainty about a target is more salient, source primes are more likely recruited to interpret target information, thus producing the metaphoric congruency effect in target perception. They had university freshmen list the reasons why they had decided to attend their current university in an upward or a downward orientation and then report how satisfied they felt about their decision. Based on the epistemic account, participants recruit spatial position (top-positive/ bottom-negative) to evaluate the satisfaction for their decision of attending their current university only when they feel uncertainty about the value of their college life. Keefer et al. made the uncertainty more salient by asking the participants to describe some uncertainties they could imagine for their life after graduating from college (e.g., whether they would find a good job) prior to the main task. They found that participants who were nudged into focusing on college-relevant uncertainties reported more satisfaction with their decision in the upward orientation condition than in the downward orientation condition. However, this difference did not occur when participants were asked to describe what would happen to them when they placed books on shelves prior to the main task (i.e., control condition). These results suggested that conceptual metaphors are involved in the representation of abstract social concepts when concrete concepts may help reduce their uncertainties (see also Keefer et al. 2014; Landau et al. 2014, 2015). According to the epistemic account, the magnitude of the metaphoric congruency effect depends on the extent to which participants could use metaphoric association to reduce uncertainty when making target judgments. Participants might be more likely to use spatial-valence metaphoric association when they were more uncertain about target's word valence in the valence judgment task. When the targets are in weak (vs. strong) valence, participants might feel more uncertain about the correct responses, so they would rely more on the spatial-valence metaphoric association to respond, and in turn, produce a larger metaphoric congruency effect. Given that equal congruency proportion (i.e., spatial information does not inform valence judgment) might induce more uncertainty on target's word valence than high congruency proportion, participants would make more use of spatial-valence metaphoric association to reduce the uncertainty of target's word valence in the equal, rather than high, congruency proportion condition, such that they would show a larger metaphoric congruency effect in the equal (vs. high) congruency proportion condition.

\section{The present study}

In three experiments, we investigated whether the spatialvalence metaphoric congruency effect may be attributed to the spreading activation between spatial concept and valence concept (activation account), the extent to which the spatial-valence metaphoric association is relevant to the task demand; that is, metaphoric association is more likely used when doing so can facilitate decision making (relevance account), and/or the epistemic function that a conceptual metaphor serves to reduce the uncertainty associated with valence concepts (epistemic account). We also discuss whether theoretical accounts of conceptual metaphors, such as Santiago et al.'s (2012) Coherent Working Models theory and Lakens' (2012) polarity correspondence account, could accommodate the current findings in "General discussion" section.

Chinese-English bilinguals were recruited as participants because this group is the most representative for university student population in Hong Kong. We manipulated congruency proportion, target eccentricity, and valence strength in a word valence judgment task (Meier \& Robinson 2004, Study 1). In this task, participants first see a central fixation and then two successive fixations at about 1.5 and $3.0 \mathrm{in}$. above or below the central fixation (as the spatial prime). Then a target word appears at about $4.0 \mathrm{in}$. above or below the center with the same direction as the prior two fixations. Participants are instructed to judge the valence of the target (positive or negative) by pressing a key. This task was found to produce a robust spatial-valence metaphoric congruency effect even when targets were presented in English in our participant population (Huang et al. 2014; Huang \& Tse 2015; see also Dudschig et al. 2014).

In Experiment 1, we manipulated congruency proportion at the macro, list level to vary the task demand or uncertainty that participants feel when making valence 
judgments. Targets were presented equally often in the congruent and incongruent positions ( 0.50 in congruency proportion) or more often in the congruent position $(0.75$ in congruency proportion). According to the epistemic account, equal, relative to high, congruency proportion might lead participants to rely more on the spatial-valence metaphoric association to make valence judgments to reduce the uncertainty of target's word valence, thereby producing a larger metaphoric congruency effect. In contrast, according to the relevance account, the metaphoric association is more relevant to the task demand in the high congruency proportion condition, so participants might more likely follow the metaphoric association to make valence judgments in the high, relative to equal, congruency proportion condition. Thus, both epistemic and relevance accounts predict a metaphoric congruency $\times$ congruency proportion interaction, but the former predicts a larger metaphoric congruency effect in equal congruency proportion condition, whereas the latter predicts the otherwise. The activation account predicts an absence of such interaction because congruency proportion being manipulated at the list level should not affect the strength of metaphoric association.

In Experiment 2, we manipulated target eccentricity to vary the strength of metaphoric association by presenting the target in the top/bottom position that is near or far away from the center of the screen. Given that all targets were strong in valence strength, they should be more associated with extreme verticality than with moderate verticality. If targets appearing far away from the center are activated more strongly by spatial prime than those appearing near the center, the activation account predicts that targets appearing in the more extreme position would trigger a larger metaphoric congruency effect than those appearing in the less extreme position. In contrast, as uncertainties associated with target's word valence should be similar whether the target appears far away from or near the center of the screen, the epistemic account predicts no influence of target eccentricity on the metaphoric congruency effect as participants would be equally likely to trigger the metaphoric association to judge the target's word valence regardless of where it appears. Given that the location where the target appears should not affect the relevance of metaphoric association to valence judgment, the relevance account also predicts no target eccentricity $\times$ metaphoric congruency interaction.

In Experiment 3, we manipulated valence strength to simultaneously vary the strength of metaphoric association, the relevance of metaphoric association to the task demand, and the uncertainty that participants feel when making valence judgments. Given that the strength of the spatial-valence metaphoric association is highly correlated with valence strength, the activation account predicts a larger metaphoric congruency effect when valence strength is stronger. The metaphoric association should be more relevant to the task demand for targets with strong valence than for those with weak valence, so the relevance account also predicts a valence strength $\times$ metaphoric congruency interaction. In contrast, the epistemic account predicts such interaction with an opposite pattern. As participants experience more uncertainties when judging targets with weaker valence, they should make use of the metaphoric association more often when target's word valence is uncertain (i.e., weak, e.g., mother and storm) than when it is certain (i.e., strong, e.g., excellence and disaster). The predictions of the three accounts for the three experiments are summarized in Table 1.

\section{General methods}

\section{Participants}

Chinese-English bilingual students with normal or corrected-to-normal vision in Chinese University of Hong Kong (CUHK) participated in exchange for monetary compensation (about 6.4 USD). All experiments were approved by CUHK Survey and Behavioral Research Ethics Committee. Informed consent was given before their participation. Each participant performed only one of the three experiments.

\section{Stimuli}

Target words were selected from a norming task, in which 48 CUHK Chinese-English bilingual students, who did not participate in any of our experiments, gave ratings on a 6-point scale to 696 English words selected from previous studies

Table 1 Summary for the manipulations and the predictions of the spatial-valence metaphoric congruency effect in Experiments 1-3

\begin{tabular}{lll}
\hline Account & Activation & Epistemic \\
\hline $\begin{array}{ll}\text { Experiment 1 } \\
\text { Congruency proportion }\end{array}$ & High congruency proportion $=$ & Equal congruency proportion $>$ \\
Experiment 2 & Target far away from the center $>$ & High congruency proportion \\
Target eccentricity & Target near the center & Target far away from the center $=$ \\
Experiment 3 & Target with stronger valence $>\quad$ Target near the center & Target with weaker valence $>\quad$ Target far away from the center $=$ \\
Valence strength & Target with weaker valence & Target with stronger valence \\
\hline
\end{tabular}


(e.g., Bradley \& Lang 1999; Meier \& Robinson 2004) on four dimensions (valence, arousal, familiarity, and concreteness). The chosen target words are strong in valence in all experiments (except those in the "weak valence" condition in Experiment 3), similar to previous studies (e.g., Huang \& Tse 2015). Appendices 1 and 2 present the full set of word stimuli in all experiments.

\section{Procedure}

E-prime 2.0 running on PC-compatible computers were used for stimuli display and data collection. All stimuli were presented on a computer screen in white font (Courier New) on a black background. In each trial, after the presentation of a 300-ms central fixation, two successive fixations appeared for $300 \mathrm{~ms}$ at about 1.5 and $3.0 \mathrm{in}$. above or below the center of the screen (as the spatial prime). Then the target appeared at about 4.0 in. above or below the center with the same direction as the prior two fixations (see Experiment 2 for a different procedure for manipulating target eccentricity). Participants were asked to judge the valence of the target (positive or negative) by pressing the " $\mathrm{A}$ " or " $\mathrm{L}$ " key as accurately and as quickly as possible. The key assignment (" $\mathrm{A}$ " or " $L$ ") of the valence judgment (positive or negative) was counterbalanced between participants. A 1.5-s visual feedback message, "Incorrect", in red appeared after an incorrect response. For correct responses, a 500-ms blank screen appeared after the participant's response. To familiarize participants with the task, they were given 12 practice trials at the beginning of the experiment. These trials were identical to experimental trials, but targets in these trials were not re-used in the experimental trials. There was a self-paced break after finishing the first half of the task. In all experiments except Experiment 1's high congruency proportion condition, half of positive and negative targets appeared at the top, and the other half, at the bottom of the screen, so participants could not predict word valence based on where the target appeared. This manipulation was counterbalanced across participants.

\section{Data analyses}

Analyses were conducted on participants' responses to the experimental trials. We first excluded incorrect trials and then trials above or below 2.5 SD from individual participant's mean RT. We then standardized RTs based on individual participants' overall mean and SD using a $z$ score transformation (i.e., zRTs) to ensure that the interpretation of magnitude of the effects might not be affected by participant's overall processing speed (see Faust, Balota, Spieler, \& Ferraro 1999). According to Judd et al. (2012), conventional ANOVA for analyses on participant-level data might fail to account for uncertainty associated with item sampling (i.e., treating items as fixed rather than random), possibly resulting in biased estimates of effects. Thus, we fit our data into a linear mixed-effects (LME) model that treat both item and participant as random factors simultaneously. zRTs or accuracies (as a binary variable) were fitted using lme4 package (Bates et al. 2015) in $\mathrm{R}$ and $p$ values were obtained for fixed effects using lmerTest package (Kuznetsova, Brockhoff, \& Christensen 2016). Extraneous variables (word length, familiarity, arousal, and concreteness) were first centered and entered as covariates. The main effects of valence, position, and congruency proportion/target eccentricity/valence strength and their interaction terms were entered as fixed effects. The random intercepts and slopes for participants and random intercepts for items were also included in the model. This mixed model with crossed random effects allows for generalization to future studies with different items and participants (see also Lim, Yap, \& Tse 2020 , for an example). Nevertheless, the results of conventional ANOVA on participant-level or item-level data that treats participant or item as a random factor are reported in Appendices. The consistency in the results of ANOVA and LME analyses suggests that the findings would not be significantly different after controlling for the extraneous variables (e.g., concreteness of target words).

\section{Experiment 1: congruency proportion}

\section{Methods}

A 2 (valence: positive or negative, within participants) $\times 2$ (position: top or bottom, within participants) $\times 2$ (congruency proportion: high 0.75 or equal 0.50 , between participants) mixed-factor design was used. One hundred and ninety-two participants were recruited and randomly assigned to either high or equal congruency proportion condition. (Participants' age and gender information were not recorded in this experiment, although they were presumably similar to those in Experiments 2 and 3.) Based on normed ratings, 96 strongly positive and 96 strongly negative words were selected, while controlling for word length and the ratings of other dimensions (see Table 2). All 192 words were randomly divided into two sets, which were assigned as experimental and filler stimuli, respectively, in a counterbalancing manner, to avoid possible differences between the stimuli in the two sets. For the experimental stimuli (48 positive and 48 negative words), half of them ( 24 positive and 24 negative words) were presented at the top of the screen, and the other half were presented at the bottom. Filler stimuli were used to increase or decrease the congruency proportion, while ensuring that the metaphoric congruency effects across conditions were computed based on the same number of observations (i.e. 24), similar to the relatedness 
Table 2 Lexical characteristics of target words in Experiments 1-3

\begin{tabular}{|c|c|c|c|c|c|c|c|c|c|c|c|c|c|c|}
\hline \multirow{2}{*}{\multicolumn{3}{|c|}{ Experiments 1 and 2}} & \multicolumn{4}{|c|}{ Positive valence } & \multicolumn{5}{|c|}{ Negative valence } & \multirow{2}{*}{\multicolumn{2}{|c|}{$t$}} & \multirow[t]{2}{*}{$p$} \\
\hline & & & \multirow{2}{*}{$\frac{\text { Mean }}{6.74}$} & \multirow{2}{*}{$\frac{\mathrm{SD}}{1.90}$} & \multicolumn{2}{|r|}{ Range } & \multicolumn{2}{|c|}{ Mean } & SD & \multicolumn{2}{|c|}{ Range } & & & \\
\hline \multicolumn{2}{|l|}{ Length } & & & & & $3-11$ & \multicolumn{2}{|c|}{6.51} & 2.06 & \multicolumn{2}{|c|}{$3-14$} & \multicolumn{2}{|c|}{.80} & 0.43 \\
\hline Familiarity & & & 4.49 & \multicolumn{2}{|l|}{0.43} & $2.70-5.20$ & \multicolumn{2}{|c|}{4.44} & 0.42 & \multicolumn{2}{|c|}{$3.60-5.30$} & \multicolumn{2}{|c|}{.78} & 0.44 \\
\hline Valence & & & 4.45 & 0.40 & & $4.04-5.46$ & \multicolumn{2}{|c|}{2.43} & 0.35 & \multicolumn{2}{|c|}{$1.63-3.29$} & \multicolumn{2}{|c|}{37.71} & $<0.01$ \\
\hline Arousal & & & 3.32 & 0.52 & & $2.38-4.79$ & \multicolumn{2}{|c|}{3.39} & 0.46 & \multicolumn{2}{|c|}{$2.08-4.21$} & \multicolumn{2}{|c|}{.99} & 0.32 \\
\hline Concreteness & & & 3.93 & 0.85 & & $2.67-5.75$ & \multicolumn{2}{|c|}{4.09} & 0.75 & \multicolumn{2}{|c|}{$2.83-5.54$} & \multicolumn{2}{|c|}{1.36} & 0.18 \\
\hline \multirow[t]{2}{*}{ Experiment 3} & \multicolumn{3}{|c|}{ Strongly positive valence } & \multicolumn{3}{|c|}{ Weakly positive valence } & \multicolumn{3}{|c|}{ Weakly negative valence } & \multicolumn{3}{|c|}{ Strongly negative valence } & \multirow[t]{2}{*}{$F$} & \multirow[t]{2}{*}{$p$} \\
\hline & Mean & $\mathrm{SD}$ & Range & Mean & $\mathrm{SD}$ & Range & Mean & SD & Range & Mean & $\mathrm{SD}$ & Range & & \\
\hline Length & 6.44 & 1.67 & $3-10$ & 6.29 & 1.82 & $3-11$ & 6.06 & 1.49 & $3-9$ & 6.50 & 1.81 & $3-11$ & .62 & 0.60 \\
\hline Familiarity & 4.18 & 0.43 & $2.67-4.71$ & 4.17 & 0.59 & $3.17-5.50$ & 4.05 & 0.55 & $2.96-5.04$ & 4.01 & 0.57 & $2.79-5.00$ & 1.14 & 0.34 \\
\hline Valence & 4.29 & 0.34 & $4.00-5.33$ & 3.78 & 0.13 & $3.54-3.96$ & 3.02 & 0.22 & $2.75-3.38$ & 2.46 & 0.21 & $1.79-2.71$ & 544.87 & $<0.001$ \\
\hline Arousal & 3.07 & 0.56 & $2.17-4.79$ & 2.97 & 0.38 & $2.33-4.13$ & 3.13 & 0.34 & $2.25-3.79$ & 3.14 & 0.27 & $2.54-3.67$ & 1.78 & 0.15 \\
\hline Concreteness & 4.03 & 0.92 & $2.67-5.75$ & 4.63 & 0.69 & $2.71-5.75$ & 4.59 & 0.73 & $3.33-5.83$ & 4.09 & 0.71 & $3.04-5.63$ & 8.16 & $<0.001$ \\
\hline
\end{tabular}

The length is in number of letters. The ratings of familiarity, valence, arousal, and concreteness are all in 6-point scales. The $t$ and $p$ values in Experiments 1 and 2 refer to the statistical significance in independent-sample $t$ tests on lexical characteristics between words with positive and negative valence. The $F$ and $p$ values in Experiment 3 refer to the statistical significance in one-way ANOVA $F$ tests on lexical characteristics among words in the four conditions

proportion manipulation in semantic priming studies (e.g., Neely \& Keefe 1989). The assignment of target words to different positions was also counterbalanced between participants and target words with different valences and positions were presented in a randomized order. Table 3 summarizes the congruency proportion manipulation. All other procedures followed the "General method", except that the congruency proportion in the 12 practice trials followed the same congruency proportion as in the experimental trials. In the high congruency proportion condition, participants were told that occurrence probabilities of positive and negative words are 0.75 and 0.25 , respectively at the top of the screen, and 0.25 and 0.75 , respectively, at the bottom of the screen. In the equal congruency proportion condition, participants were told that the occurrence probability is equal for positive and negative words $(0.50-0.50)$ at the top or bottom of the screen. This ensured participants to have explicit knowledge about the congruency proportion manipulation at the beginning of the experiment.

\section{Results}

Only experimental trials, but not filler trials, were analyzed. Due to low accuracy $(<70 \%)$, we eliminated one participant in the high congruency proportion condition and three negative and two positive target words in the following analyses. (The conclusion of our results remained the same after including the eliminated participant and items in the analyses.) The results of the descriptive statistics and conventional ANOVA are summarized in Table 4 and "Appendix 3", respectively. The syntaxes and results of LME analyses are reported in Tables 5 and 6 . We obtained a significant valence $\times$ position $\times$ congruency proportion interaction for zRTs and accuracy. Follow-up analyses showed that the valence $\times$ position interaction was significant in high congruency proportion condition (zRT: coefficient $=-0.4498$, standard error $=0.0411, p<0.0001$; accuracy: coefficient $=1.7451$, standard error $=0.1836, p<0.0001)$, but not in equal congruency proportion condition (zRT:

Table 3 Illustration of the congruency proportion manipulation in Experiment 1

\begin{tabular}{|c|c|c|}
\hline \multirow[t]{2}{*}{ Target words } & \multicolumn{2}{|l|}{ Congruency proportion (proportion of congruent trials) } \\
\hline & Equal (0.50) & High $(0.75)$ \\
\hline \multirow[t]{2}{*}{96 positive } & 48 at the top ( 24 experimental stimuli +24 filler stimuli) & 72 at the top ( 24 experimental stimuli +48 filler stimuli) \\
\hline & 48 at the bottom ( 24 experimental stimuli +24 filler stimuli) & 24 at the bottom ( 24 experimental stimuli +0 filler stimuli) \\
\hline \multirow[t]{2}{*}{96 negative } & 48 at the top (24 experimental stimuli +24 filler stimuli) & 24 at the top ( 24 experimental stimuli +0 filler stimuli) \\
\hline & 48 at the bottom ( 24 experimental stimuli +24 filler stimuli) & 72 at the bottom ( 24 experimental stimuli +48 filler stimuli) \\
\hline
\end{tabular}


Table 4 Descriptive statistics in Experiment 1

\begin{tabular}{|c|c|c|c|c|c|c|c|c|c|}
\hline & \multirow{3}{*}{$\begin{array}{l}\text { Congruency proportion } \\
\text { Valence/position }\end{array}$} & \multicolumn{4}{|l|}{ Equal } & \multicolumn{4}{|l|}{ High } \\
\hline & & \multicolumn{2}{|c|}{ Bottom } & \multicolumn{2}{|l|}{ Top } & \multicolumn{2}{|c|}{ Bottom } & \multicolumn{2}{|l|}{ Top } \\
\hline & & Mean & SD & Mean & SD & Mean & SD & Mean & SD \\
\hline \multirow[t]{2}{*}{ RT (ms) } & Negative & 870 & 204 & 853 & 197 & 875 & 209 & 911 & 217 \\
\hline & Positive & 875 & 216 & 865 & 220 & 943 & 229 & 866 & 215 \\
\hline \multirow[t]{2}{*}{ Error rate $(\%)$} & Negative & 8.46 & 7.87 & 8.16 & 7.00 & 5.25 & 5.99 & 9.99 & 9.87 \\
\hline & Positive & 7.13 & 5.83 & 7.42 & 7.33 & 9.89 & 9.38 & 4.29 & 5.41 \\
\hline
\end{tabular}

The values are based on participant data. Although RTs were reported for the ease of interpretation, z-transformed RTs were submitted for the data analyses coefficient $=0.0025$, standard error $=0.0404, p=0.9507$; accuracy: coefficient $=-0.0864$, standard error $=0.1598$, $p=0.5889$ ). In summary, we obtained a significant metaphoric congruency effect when congruency proportion was high (56 ms, $5.17 \%$ ) but not when it was equal ( $-4 \mathrm{~ms}$, $-0.3 \%)$. This is consistent with relevance account, but not epistemic or activation account. However, we failed to obtain the metaphoric congruency effect in the equal congruency proportion condition. To test the reliability of our experimental materials, we used the same set of materials in Experiment 2, where target eccentricity was manipulated.
(See also a follow-up experiment on this reported in "General discussion" section)

\section{Experiment 2: target eccentricity}

\section{Methods}

A 2 (valence: positive or negative) $\times 2$ (position: top or bottom) $\times 2$ (target eccentricity: far or near) repeated-measures design were used. Totally 192 participants were recruited

Table 5 LME model estimates (based on zRT) for main and interaction effects in Experiment 1

\begin{tabular}{|c|c|c|c|}
\hline Random effects & Variance & & SD \\
\hline \multicolumn{4}{|l|}{ Items } \\
\hline Intercept & 0.0817 & & 0.2858 \\
\hline Congruency proportion & 0.0000 & & 0.0000 \\
\hline \multicolumn{4}{|l|}{ Participants } \\
\hline Intercept & 0.0000 & & 0.0000 \\
\hline Concreteness & 0.0034 & & 0.0584 \\
\hline Arousal & 0.0090 & & 0.0950 \\
\hline Familiarity & 0.0313 & & 0.1770 \\
\hline Word length & 0.0009 & & 0.0305 \\
\hline Fixed effects & Coefficient & Standard error & $p$ value \\
\hline Intercept & 0.0339 & 0.0363 & 0.3509 \\
\hline Word length & 0.0723 & 0.0117 & $<0.001$ \\
\hline Familiarity & -0.4424 & 0.0560 & $<0.001$ \\
\hline Arousal & -0.2420 & 0.0512 & $<0.001$ \\
\hline Concreteness & 0.0502 & 0.0311 & 0.1086 \\
\hline Position & -0.0694 & 0.0289 & 0.0165 \\
\hline Valence & 0.0264 & 0.0514 & 0.6088 \\
\hline Congruency proportion & -0.1066 & 0.0288 & $<0.001$ \\
\hline Position $\times$ valence & 0.0014 & 0.0407 & 0.9716 \\
\hline Position $\times$ congruency proportion & 0.2121 & 0.0410 & $<0.001$ \\
\hline Valence $\times$ congruency proportion & 0.2384 & 0.0409 & $<0.001$ \\
\hline Position $\times$ valence $\times$ congruency proportion & -0.4560 & 0.0576 & $<0.001$ \\
\hline
\end{tabular}

da.lmer $=\operatorname{lmer}($ Zrt2 $\sim$ Length_c + FamiliarityMean_c+ArousalMean_c + ConcreteMean_c + position $*$ valence $*$ congruency proportion + $(0+$ congruent proportionlwords $)+(0+$ Length_clSubject $)+(0+$ FamiliarityMean_clSubject $)+(0+$ ArousalMean_clSubject $)+(0+$ ConcreteMean_clSubject $)+(1 \mid$ Subject $)+(1 \mid$ words $)$, da $)$ 
Table 6 LME model estimates (based on accuracy) for main and interaction effects in Experiment 1

\begin{tabular}{|c|c|c|c|}
\hline Random effects & \multicolumn{2}{|c|}{ Variance } & SD \\
\hline \multicolumn{4}{|l|}{ Items } \\
\hline Intercept & \multicolumn{2}{|c|}{0.5861} & 0.7656 \\
\hline Congruency Proportion & \multicolumn{2}{|c|}{0.0216} & 0.1468 \\
\hline \multicolumn{4}{|l|}{ Participants } \\
\hline Intercept & \multicolumn{2}{|c|}{0.3820} & 0.6181 \\
\hline Concreteness & \multicolumn{2}{|c|}{0.0327} & 0.1807 \\
\hline Arousal & \multicolumn{2}{|c|}{0.0000} & 0.0031 \\
\hline Familiarity & \multicolumn{2}{|c|}{0.0000} & 0.0062 \\
\hline Word length & \multicolumn{2}{|c|}{0.0000} & 0.0020 \\
\hline Fixed effects & Coefficient & Standard error & $p$ value \\
\hline Intercept & 2.8077 & 0.1318 & $<0.001$ \\
\hline Word length & 0.1053 & 0.0346 & 0.0023 \\
\hline Familiarity & 0.7906 & 0.1559 & $<0.001$ \\
\hline Arousal & 0.2734 & 0.1509 & 0.0700 \\
\hline Concreteness & 0.1023 & 0.0925 & 0.2687 \\
\hline Position & 0.0480 & 0.1098 & 0.6622 \\
\hline Valence & 0.2317 & 0.1645 & 0.1590 \\
\hline Congruency proportion & 0.5733 & 0.1559 & $<0.001$ \\
\hline Position $\times$ valence & -0.0860 & 0.1608 & 0.5928 \\
\hline Position $\times$ congruency proportion & -0.7974 & 0.1629 & $<0.001$ \\
\hline Valence $\times$ congruency proportion & -0.9470 & 0.1678 & $<0.001$ \\
\hline Position $\times$ valence $\times$ congruency proportion & 1.8200 & 0.2385 & $<0.001$ \\
\hline
\end{tabular}

da.glm $=\operatorname{glmer}(\operatorname{acc} \sim$ Length_c + FamiliarityMean_c + ArousalMean_c + ConcreteMean_c + position * valence * congruency proportion $+(0+$ congruent proportionlwords $)+(0+$ Length_clSubject $)+(0+$ FamiliarityMean_clSubject $)+(0+$ ArousalMean_clSubject $)+(0+$ ConcreteMean clSubject $)+(1 \mid$ Subject $)+(1$ words $)$, da, family $=$ binomial $)$

Table 7 Descriptive statistics in Experiment 2

\begin{tabular}{|c|c|c|c|c|c|c|c|c|c|}
\hline & \multirow{3}{*}{$\begin{array}{l}\text { Target eccentricity } \\
\text { Valence/position }\end{array}$} & \multicolumn{4}{|l|}{ Near } & \multicolumn{4}{|l|}{ Far } \\
\hline & & \multicolumn{2}{|c|}{ Bottom } & \multicolumn{2}{|l|}{ Top } & \multicolumn{2}{|c|}{ Bottom } & \multicolumn{2}{|l|}{ Top } \\
\hline & & Mean & SD & Mean & $\mathrm{SD}$ & Mean & $\mathrm{SD}$ & Mean & $\mathrm{SD}$ \\
\hline \multirow[t]{2}{*}{$\mathrm{RT}$ (ms) } & Negative & 835 & 168 & 828 & 170 & 817 & 159 & 823 & 168 \\
\hline & Positive & 826 & 169 & 814 & 177 & 824 & 162 & 819 & 170 \\
\hline \multirow[t]{2}{*}{ Error rate $(\%)$} & Negative & 8.08 & 6.58 & 7.93 & 6.77 & 7.37 & 6.17 & 7.79 & 6.06 \\
\hline & Positive & 7.08 & 6.42 & 7.06 & 6.33 & 7.85 & 6.83 & 6.76 & 6.08 \\
\hline
\end{tabular}

The values are based on participant data. Although RTs were reported for the ease of interpretation, z-transformed RTs were submitted for the data analyses (mean age 19.93, SD 1.59, 141 female). The target words were the same as those in Experiment 1. All other procedures followed the "General method", except that in the far (or near) condition, two successive fixations appeared at about 2.5 (or 0.5 ) and 5.0 (or 1.0) in. above or below the center of the screen. Then the target appeared at about 6.0 (or 2.0) in. above or below the center with the same direction as the prior two fixations. Positive and negative targets were presented twice, once in the near condition and once in the far condition. The assignments of target words to top/ down positions were counterbalanced between participants and target words in different conditions were presented in a randomized order.

\section{Results}

Due to low accuracy $(<70 \%)$, we eliminated two positive target words in the following analyses (The conclusion of our results remained the same after including the eliminated items in the analyses). The results of descriptive 
Table 8 LME model estimates (based on zRT) for main and interaction effects in Experiment 2

\begin{tabular}{|c|c|c|c|}
\hline Random effects & \multicolumn{2}{|c|}{ Variance } & SD \\
\hline \multicolumn{4}{|l|}{ Items } \\
\hline Intercept & \multicolumn{2}{|c|}{0.0500} & 0.2236 \\
\hline \multicolumn{4}{|l|}{ Participants } \\
\hline Intercept & \multicolumn{2}{|c|}{0.0000} & 0.0000 \\
\hline Concreteness & \multicolumn{2}{|c|}{0.0010} & 0.0314 \\
\hline Arousal & \multicolumn{2}{|c|}{0.0029} & 0.0541 \\
\hline Familiarity & \multicolumn{2}{|c|}{0.0198} & 0.1407 \\
\hline Word length & \multicolumn{2}{|c|}{0.0005} & 0.0222 \\
\hline Fixed effects & Coefficient & Standard error & $p$ value \\
\hline Intercept & 0.0633 & 0.0254 & 0.0131 \\
\hline Word length & 0.0439 & 0.0088 & $<0.001$ \\
\hline Familiarity & -0.2949 & 0.0412 & $<0.001$ \\
\hline Arousal & -0.1814 & 0.0385 & $<0.001$ \\
\hline Concreteness & -0.0021 & 0.0230 & 0.9274 \\
\hline Position & -0.0308 & 0.0149 & 0.0392 \\
\hline Valence & -0.0352 & 0.0363 & 0.3324 \\
\hline Target eccentricity & -0.0670 & 0.0149 & $<0.001$ \\
\hline Position $\times$ valence & -0.0471 & 0.0212 & 0.0260 \\
\hline Position $\times$ target eccentricity & 0.0462 & 0.0211 & 0.0284 \\
\hline Valence $\times$ target eccentricity & 0.0572 & 0.0211 & $<0.001$ \\
\hline Position $\times$ valence $\times$ target eccentricity & -0.0005 & 0.0299 & 0.9874 \\
\hline
\end{tabular}

da.lmer $=\operatorname{lmer}(Z r t 2 \sim$ Length_c + FamiliarityMean_c + ArousalMean_c + ConcreteMean_c + position * valence $*$ target eccentricity $+(0+$ Length_ clSubject $)+(0+$ FamiliarityMean_clSubject $)+(0+$ ArousalMean_clSubject $)+(0+$ ConcreteMean_clSubject $)+(1 \mid$ Subject $)+(1 \mid$ words $)$, da $)$

statistics and conventional ANOVA are summarized in Table 7 and "Appendix 4", respectively. The syntaxes and results of LME analyses are reported in Tables 8 and 9. We obtained significant valence $\times$ position interaction, but not valence $\times$ position $\times$ target eccentricity interaction in $\mathrm{zRTs}$, and a significant valence $\times$ position $\times$ target eccentricity interaction in accuracy. Follow-up analyses for accuracy showed significant valence $\times$ position interaction in far condition (coefficient $=0.2526$, standard error $=0.0828, p<0.01$ ), but not in near condition (coefficient $=-0.0166$, standard error $=0.0827, p=0.8405$ ). In summary, we obtained an overall small (4 ms) yet significant metaphoric congruency effect in zRTs and the effect was not modulated by target eccentricity. This finding is consistent with epistemic and relevance accounts, but not activation account. However, for accuracy we found a significant metaphoric congruency effect when targets were presented in the far location $(0.76 \%)$ but not when it was presented in the near location $(-0.07 \%)$, which is in line with activation account, but not epistemic or relevance account. In Experiment 3, we further tested the activation, epistemic, and relevance accounts by manipulating the valence strength of target words.

\section{Experiment 3: valence strength}

\section{Methods}

A 2 (valence: positive or negative) $\times 2$ (position: top or bottom) $\times 2$ (valence strength: strong or weak) repeatedmeasures design was used. Totally 192 participants were recruited (mean age 20.21, SD 1.55, 128 female). Based on normed ratings we selected 48 strongly positive and 48 strongly negative words for strong valence condition and 48 weakly positive and 48 weakly negative words for weak valence condition (see Table 2). The ratings of valence among all four word types significantly differed with each other (all $p s<0.01$ ). While word length, ratings of familiarity and arousal were matched across four word types, due to limited word pool we could not do that between strong and weak valence words in concreteness ratings. The strong valence words were less concrete than the weak valence words (It is noteworthy that within words with strong or weak valence, the concreteness was wellmatched between positive and negative words). Nevertheless, we considered that if the overall results remained the same in conventional ANOVAs and LME analyses, in the latter of which lexical characteristics listed in Table 2 
Table 9 LME model estimates (based on accuracy) for main and interaction effects in Experiment 2

\begin{tabular}{|c|c|c|c|}
\hline Random effects & \multicolumn{2}{|c|}{ Variance } & SD \\
\hline \multicolumn{4}{|l|}{ Items } \\
\hline Intercept & \multicolumn{2}{|c|}{0.6286} & 0.7928 \\
\hline \multicolumn{4}{|l|}{ Participants } \\
\hline Intercept & \multicolumn{2}{|c|}{0.5189} & 0.7204 \\
\hline Concreteness & \multicolumn{2}{|c|}{0.0251} & 0.1583 \\
\hline Arousal & \multicolumn{2}{|c|}{0.0685} & 0.2618 \\
\hline Familiarity & \multicolumn{2}{|c|}{0.1461} & 0.3823 \\
\hline Word length & \multicolumn{2}{|c|}{0.0026} & 0.0510 \\
\hline Fixed effects & Coefficient & Standard error & $p$ value \\
\hline Intercept & 2.9240 & 0.1060 & $<0.001$ \\
\hline Word length & 0.0641 & 0.0319 & 0.0445 \\
\hline Familiarity & 0.7803 & 0.1456 & $<0.001$ \\
\hline Arousal & 0.2118 & 0.1404 & 0.1315 \\
\hline Concreteness & 0.1145 & 0.0836 & 0.1707 \\
\hline Position & 0.0189 & 0.0567 & 0.7388 \\
\hline Valence & 0.2417 & 0.1325 & 0.0682 \\
\hline Target eccentricity & 0.1088 & 0.0573 & 0.0577 \\
\hline Position $\times$ valence & -0.0114 & 0.0833 & 0.8909 \\
\hline Position $\times$ target eccentricity & -0.0866 & 0.0807 & 0.2833 \\
\hline Valence $\times$ target eccentricity & -0.2350 & 0.0827 & $<0.001$ \\
\hline Position $\times$ valence $\times$ target eccentricity & 0.2655 & 0.1176 & 0.0239 \\
\hline
\end{tabular}

da.glm $=$ glmer(acc $\sim$ Length_c + FamiliarityMean_c + ArousalMean_c + ConcreteMean_c + position * valence $*$ target eccentricity $+(0+$ Length_ clSubject $)+(0+$ FamiliarityMean_clSubject $)+(0+$ ArousalMean_clSubject $)+(0+$ ConcreteMean_clSubject $)+(1 \mid$ Subject $)+(1 \mid$ words $)$, da, family = binomial)

except valence were statistically controlled, this discrepancy in concreteness ratings might not be significant enough to influence our results. All other procedures followed the "General method". The assignments of target words with different valence strengths to different positions were counterbalanced between participants and target words in different conditions were presented in a randomized order.

\section{Results}

Due to low accuracy $(<70 \%)$, we eliminated 2 strongly negative, 3 strongly positive, 11 weakly negative, and 9 weakly positive target words and 9 participants in the following analyses (The conclusion of our results remained the same after including the eliminated participant and items in the analyses). The results of descriptive statistics and conventional ANOVA are summarized in Table 10 and "Appendix 5", respectively. The syntaxes and results of LME analyses are reported in Tables 11 and 12. We obtained a marginal valence $\times$ position $\times$ valence strength interaction in zRTs. Follow-up analyses showed that the valence $\times$ position interaction was significant for targets with strong valence (coefficient $=-0.0749$, standard error $=0.0296, p=0.0113$ ), but not for those with weak valence (coefficient $=0.0007$, standard error $=0.0358, p=0.9851$ ). For accuracy, the position $\times$ valence, but not valence $\times$ position $\times$ valence strength, interaction was significant. In summary, we found a significant metaphoric congruency effect in zRTs when target's word valence was strong $(12 \mathrm{~ms})$ but not when it was weak $(-2 \mathrm{~ms})$, in line with relevance and activation accounts, but not epistemic account. For accuracy, we found an overall metaphoric congruency effect $(0.90 \%)$, which was not modulated by valence strength.

\section{General discussion}

The overarching goal of the current three experiments was to investigate whether spatial-valence metaphoric congruency effect in a word valence judgment task could be attributed to the spreading activation between spatial concept and valence concept (activation account), to the extent to which the spatial-valence metaphoric association is relevant to the task demand (relevance account), and/or to the epistemic function that a conceptual metaphor serves to reduce the uncertainty associated with valence concepts (epistemic account). Results showed that the metaphoric congruency 
Table 10 Descriptive statistics in Experiment 3

\begin{tabular}{|c|c|c|c|c|c|c|c|c|c|}
\hline & \multirow{3}{*}{$\begin{array}{l}\text { Valence strength } \\
\text { Valence/position }\end{array}$} & \multicolumn{4}{|l|}{ Strong } & \multicolumn{4}{|l|}{ Weak } \\
\hline & & \multicolumn{2}{|c|}{ Bottom } & \multicolumn{2}{|l|}{ Top } & \multicolumn{2}{|c|}{ Bottom } & \multicolumn{2}{|l|}{ Top } \\
\hline & & Mean & SD & Mean & SD & Mean & SD & Mean & SD \\
\hline \multirow[t]{2}{*}{ RT (ms) } & Negative & 982 & 243 & 982 & 262 & 1017 & 261 & 1002 & 253 \\
\hline & Positive & 970 & 230 & 947 & 234 & 1034 & 296 & 1023 & 277 \\
\hline \multirow[t]{2}{*}{ Error rate $(\%)$} & Negative & 10.68 & 8.64 & 12.26 & 9.61 & 14.08 & 11.25 & 15.25 & 11.15 \\
\hline & Positive & 9.08 & 8.42 & 9.67 & 8.03 & 15.05 & 11.27 & 13.80 & 10.69 \\
\hline
\end{tabular}

The values are based on participant data. Although RTs were reported for the ease of interpretation, z-transformed RTs were submitted for the data analyses

Table 11 LME model estimates (based on zRT) for main and interaction effects in Experiment 3

\begin{tabular}{|c|c|c|c|}
\hline \multicolumn{2}{|l|}{ Random effects } & Variance & \multirow[t]{2}{*}{ SD } \\
\hline Items & & & \\
\hline Intercept & \multicolumn{2}{|c|}{0.0631} & 0.2513 \\
\hline \multicolumn{4}{|l|}{ Participants } \\
\hline Intercept & \multicolumn{2}{|c|}{0.0000} & 0.0000 \\
\hline Concreteness & \multicolumn{2}{|c|}{0.0012} & 0.0341 \\
\hline Arousal & \multicolumn{2}{|c|}{0.0098} & 0.0991 \\
\hline Familiarity & \multicolumn{2}{|c|}{0.0246} & 0.1569 \\
\hline Word length & \multicolumn{2}{|c|}{0.0011} & 0.0335 \\
\hline Fixed effects & Coefficient & Standard error & $p$ value \\
\hline Intercept & 0.0892 & 0.0461 & 0.0548 \\
\hline Word length & 0.0872 & 0.0131 & $<0.001$ \\
\hline Familiarity & -0.3884 & 0.0434 & $<0.001$ \\
\hline Arousal & -0.1073 & 0.0575 & 0.0638 \\
\hline Concreteness & 0.0487 & 0.0289 & 0.0938 \\
\hline Position & -0.0399 & 0.0247 & 0.1063 \\
\hline Valence & 0.0739 & 0.0646 & 0.2537 \\
\hline Valence strength & -0.1380 & 0.0614 & 0.0257 \\
\hline Position $\times$ valence & 0.0015 & 0.0344 & 0.9658 \\
\hline Position $\times$ valence strength & 0.0315 & 0.0329 & 0.3385 \\
\hline Valence $\times$ valence strength & -0.0366 & 0.0851 & 0.6672 \\
\hline Position $\times$ valence $\times$ valence strength & -0.0777 & 0.0460 & 0.0909 \\
\hline
\end{tabular}

da.Imer $=\operatorname{lmer}(Z r t 2 \sim$ Length_c + FamiliarityMean_c + ArousalMean_c + ConcreteMean_c + position * valence * valence strength $+(0+$ Length_ clSubject $)+(0+$ FamiliarityMean_clSubject $)+(0+$ ArousalMean_clSubject $)+(0+$ ConcreteMean_clSubject $)+(1 \mid$ Subject $)+(1 \mid$ words $)$, da $)$

effect was larger when congruency proportion was high (vs. equal) and for targets with stronger (vs. weaker) valence, but it was not modulated by target eccentricity in zRTs. Taken as a whole, the results of the three experiments were better accommodated by the relevance account, but not activation or epistemic account.

It is important to first discuss why we did not obtain a significant metaphoric congruency effect in Experiment 1 's equal congruency proportion condition. This result might be attributed to (some of) the following reasons: (a) insufficient statistical power due to smaller sample size, (b) fewer observations per condition, and (c) the highlight of equal congruency proportion in the experimental instruction. Regarding the statistical power, as none of previous studies on spatial-valence metaphoric congruency effect took into account the factors of our interest, we only examined whether our experiments had enough power to detect the metaphoric congruency effect in each of the conditions, rather than to detect the interaction associated with the metaphoric congruency effect. With $N$ of 40 and Cohen's $d$ of 0.33 for the metaphoric congruency effect, which was estimated from the $F$ value (4.47, 
Table 12 LME model estimates (based on accuracy) for main and interaction effects in Experiment 3

\begin{tabular}{|c|c|c|c|}
\hline Random effects & \multicolumn{2}{|c|}{ Variance } & SD \\
\hline \multicolumn{4}{|l|}{ Items } \\
\hline Intercept & \multicolumn{2}{|c|}{0.6329} & 0.7955 \\
\hline \multicolumn{4}{|l|}{ Participants } \\
\hline Intercept & \multicolumn{2}{|c|}{0.3038} & 0.5512 \\
\hline Concreteness & \multicolumn{2}{|c|}{0.0241} & 0.1553 \\
\hline Arousal & \multicolumn{2}{|c|}{0.2258} & 0.4752 \\
\hline Familiarity & \multicolumn{2}{|c|}{0.1411} & 0.3756 \\
\hline Word length & \multicolumn{2}{|c|}{0.0028} & 0.0528 \\
\hline Fixed effects & Coefficient & Standard error & $p$ value \\
\hline Intercept & 2.1490 & 0.1514 & $<0.001$ \\
\hline Word length & 0.0339 & 0.0417 & 0.4159 \\
\hline Familiarity & 0.7535 & 0.1384 & $<0.001$ \\
\hline Arousal & 0.0245 & 0.1884 & 0.8967 \\
\hline Concreteness & -0.0374 & 0.0937 & 0.6896 \\
\hline Position & -0.1033 & 0.0715 & 0.1483 \\
\hline Valence & -0.0649 & 0.2044 & 0.7510 \\
\hline Valence strength & 0.4653 & 0.1965 & 0.0179 \\
\hline Position $\times$ valence & 0.2032 & 0.1002 & 0.0425 \\
\hline Position $\times$ valence strength & -0.0718 & 0.1011 & 0.4772 \\
\hline Valence $\times$ valence strength & 0.1568 & 0.2739 & 0.5671 \\
\hline Position $\times$ valence $\times$ valence strength & -0.1013 & 0.1461 & 0.4884 \\
\hline
\end{tabular}

da.glm $=$ glmer $($ acc $~$ Length_c + FamiliarityMean_c + ArousalMean_c + ConcreteMean_c + position * valence * valence strength $+(0+$ Length clSubject $)+(0+$ FamiliarityMean_clSubject $)+(0+$ ArousalMean_clSubject $)+(0+$ ConcreteMean_clSubject $)+(1 \mid$ Subject $)+(1$ lwords $)$, da, family = binomial)

i.e., $t$ of 2.11) reported in Huang et al. (2014) Study $1 \mathrm{~b}$ that used a similar task and participant pool as the current study, the power to detect the basic metaphoric congruency effect in each of the conditions was 0.62 (with $N=95$ or 96), 0.88 (with $N=192$ ), and 0.86 (with $N=183$ ), in our Experiments 1-3, respectively, based on Table 2.3.5 in Cohen (1988). While Experiments 2 and 3 have sufficient power to detect the metaphoric congruency effect in each of the conditions (as the variable was manipulated within participants), this was not the case in Experiment 1 , where congruency proportion was manipulated between participants. Apart from smaller sample size, the number of observations per condition in Experiment 1 was reduced by half (i.e., 48), as compared with other two experiments (i.e., 96), because half of the words was assigned to be filler trials and thus not included in the analyses. Finally, in Experiment 1 participants were explicitly introduced about congruent and incongruent trials and told that these two types of trials would be equal or high in proportion. This explicit instruction was not used in Experiment 2 or 3 or in our previous experiments (e.g., Huang et al. 2014).

We conducted a follow-up experiment to test whether the basic metaphoric congruency effect could be replicated in the equal congruency proportion condition when (a) the sample size is large enough to provide sufficient power (i.e., 192 participants to reach statistical power of 0.88 ), (b) the number of observation is as many as those in Experiments 2 and 3 (i.e., 96 per condition), and (c) there is no explicit instruction about the congruent or incongruent trials and their proportion. Due to coronavirus outbreak in Hong Kong (January-March 2020), we were not able to conduct this experiment in our laboratory. Instead, we programmed this experiment using PsychoPy 3.2.4 (Peirce, Gray, Simpson et al. 2019, see also Anwyl-Irvine, Dalmaijer, Hodges, \& Evershed 2020; Bridges, Pitiot, MacAskill, \& Pierce 2020), which was used in previous online experiments (e.g., Gallant 2020; Potthoff, La Face, \& Schienle 2020), and ran the experiment in an online platform (Pavlovia). The design and procedure were highly similar to those in Experiment 1's equal congruency proportion condition except that 192 participants were recruited (mean age 20.29, SD 2.32, 138 female), the number of observation was 96 per condition (i.e., including both experimental and "filler" trials in the analyses) and the instruction did not state any information about congruency or the proportion of congruent and incongruent trials (i.e., the same instruction as in Experiments 2 
and 3 and our previous works, e.g., Huang et al. 2014).[It is noteworthy that the parameters, such as font type (Arial), of the programs created by PsychoPy might be different from those by E-Prime, i.e., the software that we used for the experiments conducted in the laboratory. Besides, we could not strictly control the size of the computer screen when participants did the task in the online platform, Pavlovia, so the font size and position of the stimuli might not be identical to those used in Experiment 1 conducted in the laboratory.] Due to low accuracy $(<70 \%)$, we eliminated one participant and four negative and two positive target words in the following analyses. The results of descriptive statistics and conventional ANOVA are summarized in Table 13 and "Appendix 6", respectively. The overall SD in RTs was larger in this follow-up experiment than Experiments 1-3, perhaps due to the difference between collecting data online vs. in the laboratory. Nonetheless, given that our RT analyses were based on standardized RTs, the interpretation of our findings should be less affected by individual participants' overall processing speed. The syntaxes and results of LME analyses are reported in Tables 14 and 15 . We obtained a significant valence $\times$ position for zRTs and accuracy, replicating the typical metaphoric congruency effect. We combined the data of this follow-up experiment with the high congruency proportion condition in Experiment 1 and tested whether the metaphoric congruency effect was still significantly stronger in the high congruency proportion condition, with caution that there were differences in procedure
Table 13 Descriptive statistics in experiment 1's follow-up experiment

\begin{tabular}{lllllll}
\hline & Valence/position & \multicolumn{2}{l}{ Bottom } & & & \multicolumn{2}{l}{ Top } \\
& & Mean & SD & & Mean & SD \\
\hline RT (ms) & Negative & 930 & 470 & & 925 & 491 \\
& Positive & 941 & 510 & & 897 & 386 \\
Error rate (\%) & Negative & 6.82 & 5.87 & 7.42 & 6.25 \\
& Positive & 6.89 & 5.13 & & 6.41 & 5.04 \\
\hline
\end{tabular}

The values are based on participant data. Although RTs were reported for the ease of interpretation, z-transformed RTs were submitted for the data analyses

(e.g., collected in laboratory vs. online platform) and design (e.g., twice as many observations per condition in Experiment 1's follow-up experiment) between the two conditions. The metaphoric congruency effect was stronger in the high congruency proportion condition in Experiment $1(56 \mathrm{~ms}$, $5.17 \%$ ) than the equal congruency proportion condition in the follow-up experiment ( $19 \mathrm{~ms}, 0.54 \%$ ), both $p s<0.001$, $\eta_{\mathrm{p}}{ }^{2}>0.13$, consistent with our conclusion in Experiment 1 . In short, we obtained a significant metaphoric congruency effect in the equal congruency proportion condition. This suggests that researchers should take care of the statistical power (and sample size) and number of observations per condition in experiments that examine the metaphoric congruency effect in future studies.

Table 14 LME model estimates (based on zRT) for main and interaction effects in Experiment 1's Follow-up Experiment

\begin{tabular}{|c|c|c|c|}
\hline Random effects & & Variance & $\mathrm{SD}$ \\
\hline \multicolumn{4}{|l|}{ Items } \\
\hline Intercept & & 0.0707 & 0.2659 \\
\hline \multicolumn{4}{|l|}{ Participants } \\
\hline Intercept & & 0.0000 & 0.0000 \\
\hline Concreteness & & 0.0021 & 0.0454 \\
\hline Arousal & & 0.0065 & 0.0806 \\
\hline Familiarity & & 0.0366 & 0.1913 \\
\hline Word length & & 0.0006 & 0.0239 \\
\hline Fixed effects & Coefficient & Standard error & $p$ value \\
\hline Intercept & 0.0281 & 0.0299 & 0.3497 \\
\hline Word length & 0.0518 & 0.0107 & $<0.0001$ \\
\hline Familiarity & -0.3769 & 0.0531 & $<0.0001$ \\
\hline Arousal & -0.2170 & 0.0465 & $<0.0001$ \\
\hline Concreteness & 0.0585 & 0.0278 & 0.0364 \\
\hline Position & -0.0251 & 0.0148 & 0.0904 \\
\hline Valence & 0.0359 & 0.0425 & 0.3987 \\
\hline position $\times$ valence & -0.0709 & 0.0208 & 0.0007 \\
\hline
\end{tabular}

da.lmer $=\operatorname{lmer}($ Zrt2 $\sim$ Length_c + FamiliarityMean_c + ArousalMean_c + ConcreteMean_c + position $*$ valence $+(0+$ Length_clSubject $)+(0+$ FamiliarityMean_clSubject $)+(0+$ ArousalMean_clSubject $)+(0+$ ConcreteMean_clSubject $)+(1 \mid$ Subject $)+(1 \mid$ words $)$, da $)$ 
Table 15 LME model estimates (based on accuracy) for main and interaction effects in Experiment 1's follow-up experiment

\begin{tabular}{|c|c|c|c|}
\hline Random effects & & Variance & $\mathrm{SD}$ \\
\hline \multicolumn{4}{|l|}{ Items } \\
\hline Intercept & & 0.6504 & 0.8065 \\
\hline \multicolumn{4}{|l|}{ Participants } \\
\hline Intercept & & 0.4272 & 0.6536 \\
\hline Concreteness & & 0.0082 & 0.0908 \\
\hline Arousal & & 0.1082 & 0.3290 \\
\hline Familiarity & & 0.1576 & 0.3971 \\
\hline Word length & & 0.0000 & 0.0000 \\
\hline Fixed effects & Coefficient & Standard error & $p$ value \\
\hline Intercept & 3.0935 & 0.1091 & $<0.0001$ \\
\hline Word length & 0.0815 & 0.0341 & 0.0170 \\
\hline Familiarity & 0.7617 & 0.1645 & $<0.0001$ \\
\hline Arousal & 0.2710 & 0.1509 & 0.0725 \\
\hline Concreteness & 0.0443 & 0.0883 & 0.6162 \\
\hline Position & -0.0978 & 0.0599 & 0.1029 \\
\hline Valence & 0.0906 & 0.1384 & 0.5125 \\
\hline Position $\times$ valence & 0.1799 & 0.0865 & 0.0375 \\
\hline
\end{tabular}

da.glm $=\operatorname{glmer}(\operatorname{acc} \sim$ Length_c + FamiliarityMean_c + ArousalMean_c + ConcreteMean_c + position valence $+(0+$ Length_clSubject $)+(0+$ FamiliarityMean_clSubject $)+(0+$ ArousalMean_clSubject $)+(0+$ ConcreteMean_clSubject $)+(1 \mid$ Subject $)+(1 \mid$ words $)$, da, family $=$ binomial $)$

\section{Implications on the activation, epistemic, and relevance accounts}

In social perception literature, there were robust evidences for the epistemic functions that conceptual metaphors play in reducing uncertainties in social perception (e.g., Keefer et al. 2014; Landau et al. 2014, 2015). If the spatial-valence conceptual metaphor also has this epistemic function, participants should be more likely to use spatial-valence metaphoric association when they are more uncertain about target's word valence in the valence judgment task. Given participants might feel more uncertain (a) when they need to judge targets with weak (vs. strong) valence and (b) when they are told that the proportion of congruent and incongruent trials is equal (vs. high), they would rely more on the spatial-valence metaphoric association to respond, and in turn, produce a larger metaphoric congruency effect for targets with weak (vs. strong) valence and when the congruency proportion is equal (vs. high). However, this prediction was not consistent with the current finding that a larger metaphoric congruency effect occurred for targets with stronger valence than those with weaker valence and in the high congruency proportion condition than in the equal congruency proportion condition. Hence, the epistemic account might not be directly generalized to explain the findings of conceptual metaphors that are not related to social perception.
To further test the activation and relevance accounts on whether metaphoric congruency effect would be larger for targets with relatively strong valence than for those with relatively weak valence, we conducted correlation analyses on our data to test the relationship between target's word valence and metaphoric congruency effect, given the relatively large range of target's word valence after collapsing across positive and negative words. We first computed the difference score by subtracting the zRT/error rates that target words presented at the top from the zRT/error rates that target words presented at the bottom, and then test whether there would be a positive correlation between this difference score and target's word valence. Target words with more negative valence would yield faster zRT and/or less error rates when they appeared at the bottom than at the top (i.e., more negative difference scores), whereas those with more positive valence would yield faster zRT and/or less error rates when they appeared at the top than at the bottom (i.e., more positive difference scores). In Experiment 1, results showed that positive and significant correlation in the high congruency proportion condition, $r=+0.56, p<0.01$ for zRT and $r=+0.46, p<0.01$ for error rates, but not in the equal congruency proportion condition, $r=+0.003, p=0.96$ for zRT and $r=-0.03, p=0.68$ for error rates. This was the case after controlling for extraneous variables (word length, arousal, concreteness, and familiarity) (high congruency proportion: $r=+0.55, p<0.01$ for zRT and $r=+0.48, p<0.01$ 
for error rates; equal congruency proportion: $r=-0.01$, $p=0.90$ for zRT and $r=-0.04, p=0.57$ for error rates). In Experiment 2, the correlation was also positive for zRT, $r=+0.14, p=0.054$, and error rates, $r=+0.25, p<0.01$, in far condition, and for zRT, $r=+0.17, p=0.02$, but not for error rates, $r<+0.01, p=0.998$, in near condition. This was the case after controlling for extraneous variables (far: $r=+0.15, p=0.047$ for zRT and $r=+0.24, p<0.01$ for error rates; near: $r=+0.16, p=0.03$ for zRT and $r=+0.02$, $p=0.84$ for error rates). In Experiment 3, the correlation was again positive for zRT, $r=+0.18, p=0.02$, and error rates, $r=+0.11, p=0.16$. This was the case after controlling for extraneous variables, $r=+0.16, p=0.04$ for zRT and $r=+0.10, p=0.20$ for error rates. Finally, in Experiment 1's follow-up experiment the correlation was positive for zRT, $r=+0.21, p<0.01$, and error rates, $r=+0.15, p=0.04$. This was the case after controlling for extraneous variables, $r=+0.20, p<0.01$ for $\mathrm{zRT}$ and $r=+0.15, p=0.04$ for error rates.

These positive correlations provided support for both activation and relevance accounts. However, the activation account might not explain why there was a stronger correlation in the high congruency proportion condition in Experiment 1 than in either target eccentricity condition, which could be regarded as equal congruency proportion condition, in Experiment 2 and in Experiment 1's followup experiment. In contrast, the relevance account argues that a marco, list-level manipulation of high congruency proportion in Experiment 1 could motivate participants to rely more on the spatial-valence metaphoric association that could facilitate their valence judgments, such that the metaphoric congruency effect was more sensitive to target's word valence in this condition than when the congruency proportion was equal in Experiment 2. This could be validated by orthogonally manipulating both congruency proportion and valence strength in future studies. On the other hand, given the generally weak correlation between valence strength and metaphoric congruency effect, one could question whether the strength of spatial-valence metaphoric association is necessarily strongly correlated with valence strength. Even though "heaven" is high in valence and highly strongly associated with vertical space, some emotion words might not have as strong association with vertical space. For example, "sunrise" might not be as high in valence as "miracle" but it might be more strongly associated with vertical space (see, e.g., Dudschig, de la Vega, \& Kaup 2015, for a similar idea). Thus, future researchers should measure more directly the association between space and valence in a large-scale norm study to classify words with positive or negative valence that are more vs. less associated with vertical space and provide a further test for the activation account.

It is noteworthy that the congruency proportion manipulation was different from those (e.g., proportion of related prime-target pairs) in semantic priming literature. Specifically, the manipulation of relatedness proportion in semantic priming paradigm was often implicit that participants were not told any information about the proportion of related prime-target pairs (e.g., Neely 1991; Neely \& Keefe 1989; Neely et al. 1989; but see Hutchison 2007). Contrary to this implicit manipulation, in our Experiment 1 participants were explicitly informed about the congruency proportion manipulation. When congruency proportion manipulation is made implicit (i.e., participants are not told any information about the proportion of congruent trials), it is possible that participants could acquire the information about congruency proportion during the experiment and use that to perform better in the task even though they do not necessarily become aware of this. It is possible that task relevance might play a role in modulating the metaphoric congruency effect only when the congruency proportion manipulation is explicit but not when it is implicit, which could be tested in future studies.

\section{Implications on the alternative accounts}

Although we focus on the activation, epistemic, and relevance accounts in the current study, it is important to speculate the implications of the current findings on other accounts in the literature even though they were not necessarily developed to explain the influence of our manipulated variables on the metaphoric congruency effects. We first consider three conceptual metaphor accounts and then two accounts outside the conceptual metaphor literature.

\section{Santiago et al.'s (2011) coherent working models theory}

According to this theory (see also Santiago et al. 2012), metaphoric congruency effect occurs only when participants' attention is directed to the source or target domain (i.e., space or valence domain in our case). This theory is quite similar to the relevance account in the way that participants should be aware of the relevance of spatial-valence metaphoric association once they (are directed to) attend to position (i.e., space) and valence of target words. In our experiments, we presented three successive fixations to orient participants' attention to the location of the forthcoming target words, so in line with the Coherent Working Models Theory, the primed spatial information had an influence on participants' subsequent valence judgments. To explain the findings regarding the effects of congruency proportion and valence strength, one could suppose that the more often the target appeared in congruent position or the stronger the target's word valence, the more likely that participants' attention would be directed to the position (analogous to the prospective expectancy mechanism in semantic priming literature, see Neely et al. 1989) or to word valence, 
the larger the metaphoric congruency effect would occur. Target eccentricity did not affect the metaphoric congruency effect because the likelihood of participants' attention being directed to the positions might be the same whether the target words appeared far away or near the center of the screen. In short, Santiago et al.'s coherent working models theory may share similar hypotheses as our relevance account and thus be supported by the current findings.

\section{Language-mediated vs. experiential origin of conceptual metaphors}

The development of source-target mapping in conceptual metaphors may be mediated by language use and/or by sensorimotor experience. The distinction between languagemediated and experiential origin of conceptual metaphors could derive different predictions for the current experiments. According to language-mediated view (e.g., Boroditsky 2000), after repeated use of metaphors in everyday language, a relational structure of the concrete, source domain may be stored at the abstract, target domain. For example, the frequent spatial expressions to talk about valence in everyday language (e.g., "cheers $u p$ " for happiness and "let down" for disappointment) could motivate the generation of analogies and guide the mapping of structure across spatial and valence domains. On the other hand, the experiential view suggests that the determining factor of conceptual metaphor development is the experiential correlation between the processing of concrete and abstract domains (e.g., Casasanto 2008; Casasanto \& Gijssels 2015; Lakoff 2008, 2012). People tap into their concrete, sensorimotor experience to make sense of abstract ideas like valence. For example, early childhood sensorimotor experience may be associated with positive emotion (e.g., standing up) or negative emotion (e.g., falling down) (e.g., Tolaas 1991). Upright postures are often associated with positive mood and slumped postures with negative mood (e.g., Oosterwijk, Rotteveel, Fischer, \& Hess 2009).

According to the language-mediated view, the metaphoric congruency effect may depend on the degree of spreading activation across spatial-valence metaphoric association, which is presumably correlated with valence strength in the current study. Thus, this view could predict a larger metaphoric congruency effect for words with stronger valence than for those with weaker valence. While Experiment 3's findings were consistent with this prediction of the language-mediated view, it is not clear how it could explain the influence of congruency proportion on the metaphoric congruency effect, as the strength of spatial-valence metaphoric association should not be influenced by list context. On the other hand, according to the experiential view, the metaphoric congruency effect may be moderated by the extent to which sensorimotor processing is (or has been) involved during (or prior to) the processing of target words. The manipulation of target eccentricity might presumably influence participants' oculomotor processing, which was stronger when target appeared in the far (vs. near) location with respect to the center of the screen. Previous studies on saccade trajectory showed that semantic processing of word valence could recruit spatial features along vertical space even though that was not relevant to task demand (e.g., Gozli, Chow, Chasteen, \& Pratt 2013). Hence, the experiential view could predict the influence of target eccentricity, with the metaphoric congruency effect being larger for targets appearing in the far location than for those appearing in the near location. Experiment 2's results were not consistent with this prediction because we did not find any significant influence of target eccentricity on the metaphoric congruency effect. It is important to note that the current experiments were not designed to test between the languagemediated view and experiential view. In fact, the predictions for some of our manipulations are not very clear (e.g., language-mediated view on the effect of target eccentricity and experiential view on the effect of valence strength). Future researchers should explore other manipulations that could more clearly distinguish the predictions of languagemediated and experiential views of conceptual metaphors.

\section{Symmetric vs. asymmetric RT pattern of the valence $\times$ position interaction}

It is worth considering whether our findings could be accommodated by Lakoff and Johnson's (1999) Conceptual Metaphor Theory and Lakens' (2012) polarity account. According to the Conceptual Metaphor Theory, spatial-valence metaphoric congruency effect occurs when participants make faster responses to positive words that appear at the top than those that appear at the bottom and to negative words that appear at the bottom than those that appear at the top. That is, the valence $\times$ position interaction occurs with a symmetric RT pattern for positive and negative words. However, some studies showed an asymmetric RT pattern: the top vs. bottom difference occurred only in positive words but not in negative words (e.g., Lakens 2011, 2012; Lynott \& Coventry 2014). This latter pattern might be accommodated better by the polarity account than by the Conceptual Metaphor Theory. According to the polarity account, each dimension consists of polar opposites (e.g., good-bad or up-down) and has a default endpoint (+ polar) and the corresponding opposite endpoint (- polar) (Proctor \& Cho 2006). The + polar endpoint (positive or top) has a processing advantage over the -polar endpoint (negative or bottom, e.g., Clark \& Chase 1974). As postulated by Lakens (2012), four types of processing advantages contribute to the occurrence of spatial-valence metaphoric congruency effect. First, people process positive words faster than negative words. 
Second, words presented at the top position are processed faster than those presented at the bottom position. Third, in a bimanual response task, responses are usually coded as yes/no, positive/negative, or true/false. Responses are faster when they are coded as + polar (yes, positive, or true) than - polar (no, negative, or false) (Clark \& Brownell 1975). Fourth, based on Proctor and Cho's polarity correspondence principle, responses are faster when the polarities of stimulus' conceptual and perceptual dimensions overlap (i.e., positive words presented at the top and negative words at the bottom) than when they do not overlap. After summing up all four types of processing advantages, the RT pattern of a spatial-valence metaphoric congruency effect is expected as follows: people may respond faster to positive words that appear at the top than at the bottom of the screen, but they may respond equally fast to negative words whether they appear at the top or at the bottom. This asymmetric RT pattern predicted by the polarity account is different from the symmetric RT pattern predicted by the Conceptual Metaphor Theory. In the current study, for the conditions that produced significant metaphoric congruency effects, we observed a symmetric RT pattern in Experiment 1's high congruency proportion condition [for positive words: $t(94)=8.73$, $p<0.01$; for negative words: $t(94)=-3.74, p<0.01$ ], consistent with the Conceptual Metaphor Theory. However, in Experiment 2's far condition and Experiment 3's strong valence condition we obtained a pattern consistent with polarity account. There was a difference between top and bottom positions in positive words, $t(191)=2.00, p=0.047$ and $t(182)=3.99, p<0.01$, respectively, but not in negative words, $t(191)=-0.95, p=0.35$ and $t(182)=0.33, p=0.74$, respectively. Finally, in Experiment 2's near condition, we found the significant difference in both positive and negative words, but they were in the same direction, $t(191)=4.82$, $p<0.01$ and $t(191)=2.02, p=0.045$. In Experiment 1's follow-up experiment, the difference in both positive and negative words were also in the same direction, but it was significant for positive words and only marginally so for negative words, $t(190)=5.11, p<0.01$ and $t(190)=1.89, p=0.06$. Hence, neither the Conceptual Metaphor Theory nor the polarity account could fully accommodate all of the current RT pattern of valence $\times$ position interaction. Besides, it awaits further development of these two accounts to explain why valence strength and congruency proportion, but not target eccentricity, could modulate the spatial-valence metaphoric congruency effect.

\section{Attentional control account}

As spatial and valence information can be in concert or in conflict in the current task, the influence of congruency proportion that we obtained in the metaphoric congruency effect in Experiment 1 may follow the pattern reported in attentional control studies (e.g., Botvinick et al. 2001; Bugg, Jacoby, \& Toth 2008). Specifically, when congruency proportion increased, participants' need of attentional control was reduced because in most of the trials they could merely follow the metaphoric association when judging the word valence. This sped up participants' RT and/or led to fewer errors to congruent trials, but might also delay their RT and/or led to more errors to incongruent trials because participants needed to recover from attempting to judge the word valence on the basis of congruent spatial information when that is actually incorrect. An observation for the cell means in Experiment 1 (see Table 4) supported this view. Compared with equal congruency proportion condition, in high congruency proportion condition participants did show longer RT and higher error rates in incongruent trials (high: 927 ms vs. equal: $864 \mathrm{~ms}$; high: $9.9 \%$ vs. equal: $7.6 \%$ ) and lower error rates (yet similar RT) in congruent trials (high: $871 \mathrm{~ms}$ vs. equal: $868 \mathrm{~ms}$; high: $4.8 \%$ vs. equal: $7.9 \%$ ). [It may not be appropriate to compare Experiment 1's high congruency proportion condition with Experiment 1's followup experiment ("equal congruency proportion" condition) due to procedural differences (e.g., number of observations per condition.)] This explained why metaphoric congruency effect was larger in the high vs. equal congruency proportion condition. While this attentional control account could explain the influence of congruency proportion on the metaphoric congruency effect in Experiment 1, it is not clear how it could accommodate the findings in Experiment 3. Given that the targets with strong or weak valence were intermixed in the task, it is not likely that participants' need of attentional control could vary trial-by-trial depending on the valence strength. Nevertheless, future research should tease apart the influence of attentional control and task relevance on the metaphoric congruency effect.

\section{Lexical priming vs. response competition}

It is important to tease apart whether the current findings could be attributed to spreading activation in lexical priming and/or response competition in categorical priming, an issue often considered in affective priming literature (e.g., Voss, Rothermund, Gast, \& Wentura 2013). The congruency effect due to spreading activation in lexical priming (hereafter the lexical priming account) is analogous to the explanation of the activation account: participants made faster valence judgments to words of congruent valence than those of incongruent valence as the activation of spatial prime (as driven by participants' sensorimotor experience-moving up or down in oculomotor processing) could spread to the target concepts via spatial-valence metaphoric association. This account postulates that priming operates at the stage of lexical access to target word: the congruent (vs. incongruent) spatial prime facilitates the encoding and identification of 
the subsequent target word, speeds up the accessibility of its semantic information, including valence, and in turns produces the metaphoric congruency effect. Hence, this lexical priming account might share the same set of predictions as the activation account for the current experiments.

In contrast, response competition in categorical priming (hereafter the response competition account) might also play a role in the congruency effect. While the spatial primes are congruent or incongruent to the target words with positive or negative valence, it is worth noting that they are also congruent or incongruent to the positive or negative response that participants make to the target words. For example, in a typical affective priming experiment, positive and negative target word being categorized according to their valence are preceded by positive or negative primes. The apparently irrelevant information of the prime might trigger participants' tendency to make a certain response. If this pre-activated response is consistent with the response required by the relevant information in the target word, response is facilitated. In contrast, if the prime activates a response being in conflict with the response that is required for the target word, there would be a delay in response. This response competition account predicts the congruency effect only when the dimension on which prime and target are related is task relevant (e.g., the current study in which the task demand, i.e., valence judgment, was related to responses that were preactivated by the spatial prime). Thus, this response competition account might share the same set of predictions as the relevance account for the current experiments.

To test the lexical priming account vs. response competition account (and similarly, the activation account vs. relevance account), the type of task may be manipulated, instead of just using the valence judgment task that always taps the target domain of spatial-valence metaphoric association. For example, lexical decision or word naming could be used (see Dudschig et al. 2015 for a similar idea). The response competition account (and the relevance account) would predict the metaphoric congruency effect only when the task is relevant to the target domain of spatial-valence metaphoric association, but the lexical priming (and the activation account) would predict the metaphoric congruency effect regardless of whether the task is relevant to the target domain of spatial-valence metaphoric association. That is, metaphoric congruency effect is supposed to occur even in the task, such as lexical decision, that does not tap the processing of word valence because the target words, not just their valence information, should have been activated as long as the spreading activation of the spatial prime occurs. On the other hand, fine-grained analyses (e.g., diffusion models in Voss et al. 2013) could be done to track different stages of conceptual metaphor processing. Specifically, lexical priming may more likely take place at the earlier stage of processing, whereas response competition may more likely occur at the later stage of processing in producing metaphoric congruency effect. This could then test between the activation account and relevance account. Nonetheless, these analytic techniques, such as diffusion model (e.g., Voss, Voss, \& Lerche 2015), quantile (e.g., de Wit \& Kinoshita 2015), vincentile (e.g., Tse, Hutchison, \& Li 2011), and ex-Gaussian RT distribution (e.g., Tse, Balota, Yap et al. 2010), have rarely been used in conceptual metaphor studies. To our knowledge, only one study has used vincentile analyses (e.g., Huang, Tse, $\&$ Xie 2018) to examine the brightness-valence metaphoric association in Stroop-like and priming tasks.

\section{Conclusion}

The present experiments tested the activation, epistemic, and relevance accounts for the spatial-valence metaphoric congruency effect. Based on three experiments, we conclude that the effect is more likely attributed to the extent to which the metaphoric association is relevant to task demand. When the activation of spatial-valence metaphoric association could facilitate the performance in the valence judgment task (e.g., when there is high proportion of congruent trials in the task and when the target's word valence is strong), people are more likely to rely on this association to make responses. Contrary to this relevance account, neither activation nor epistemic account could provide explanations to all of the current findings. Future research should use other manipulations that might affect task relevance to identify possible boundary conditions for the task relevance as the explanatory account and modify the existing accounts (e.g., Conceptual Metaphor Theory) to accommodate the modulating role of congruency proportion and valence strength in the spatial-valence metaphoric congruency effect. Other conceptual metaphors, such as brightness-valence, should also be examined to further test the validity of various accounts.

Acknowledgements This research is supported by Supportive Fund for Strategic Research, The Chinese University of Hong Kong. We thank Louis Ka-Chun Chan for his assistance in data collection.

Data availability The data that support the findings of this study are available in Open Science Framework at https://osf.io/5f3h6.

\section{Compliance with ethical standards}

Conflict of interest The authors report no conflict of interest. 


\section{Appendix 1}

\section{Experiments 1 and 2's target words}

\begin{tabular}{|c|c|c|c|c|c|c|c|}
\hline \multicolumn{4}{|l|}{ Positive } & \multicolumn{4}{|l|}{ Negative } \\
\hline Ability & Enjoyment & Loyalty & Recognition & Accident & Dust & Injury & Regret \\
\hline Abundance $* \%$ & Faith & Luxury & Refreshment & Anger & End & Insult & Rejection \\
\hline Acceptance & Fantasy & Manner & Respect & Anxiety & Evil & Jail & Robber \\
\hline Advantage & Favor & Melody & Reunion & Army $^{\$}$ & Excuse & Jealousy & Seasick \\
\hline Adventure & Glory & Millionaire & Reward & Assault & Execution $^{\$}$ & Killer & Selfishness \\
\hline Aid & Grace & Miracle & Salad & Bankrupt & Failure & Lie & Sickness \\
\hline Ambition & Ham & Nature & Scholar & Beggar & Fault & Loneliness & Slave \\
\hline Angel & Heaven & Optimism & Security & Bomb & Fear & Loser & Smallpox \\
\hline Attitude & Heritage & Option & Silk $^{\%}$ & Bullet & Fever & Loss & Starving \\
\hline Beach & Honey & Orchestra & Soul & Cancer & Fire & Misery & Stress \\
\hline Beauty & Honor & Orgasm $^{\$}$ & Spirit & Chaos & Foul & Mistake & Suicide \\
\hline Bless & Hug & Palace & Sunrise & Cockroach & Funeral & Mosquito & Surgery* \\
\hline Blossom & Humor & Pancake & Sweetheart & Crime & Garbage & Nightmare & Tease \\
\hline Breeze & Identity & Paradise & Talent & Crisis & Gossip & Obesity & Terrorist \\
\hline Capability & Idol & Party & Theory & Criticism & Guilt & $\begin{array}{l}\text { Obses- } \\
\text { sion*\$ }\end{array}$ & Theft \\
\hline Cash & Impression & Passion & Triumph & Death & Handicap & Pain & Thief \\
\hline Church & Jewel & Pasta & Twilight & Debt & Hatred & Penalty & Tobacco \\
\hline Comedy & Justice & Perfection & Vacation & Depression & Headache & Pity & Toothache \\
\hline Comfort & Kindness & Permission & Valentine & Destruction & Hell & Poison & Trash \\
\hline Crown & Kiss & Plane & Victory & Dirt & Horror & Pollution & Trouble \\
\hline Democracy & Leader & Poetry & Virtue* & Disappointment & Hunger & Poverty & Vampire \\
\hline Desire & Legend & Politeness & Warmth & Disaster & Idiot & Pressure*\$ & Victim \\
\hline Donor & Liberty & Pride & Wealth & Discomfort & Ignorance & Prison & War \\
\hline Employment & Lightbulb & Profit & Wedding & Dump & Illness & Punishment & Weapon \\
\hline
\end{tabular}

Target words with asterisk, dollar, and percentage sign were eliminated in Experiment 1, Experiment 1's follow-up experiment (see the "General discussion" section for more details), and Experiment 2's analyses, respectively, due to low accuracy $(<70 \%)$. 


\section{Appendix 2}

\section{Experiment 3's target words}

\begin{tabular}{|c|c|c|c|c|c|c|c|}
\hline \multicolumn{2}{|l|}{ Strong-negative } & \multicolumn{2}{|c|}{ Strong-positive } & \multicolumn{2}{|l|}{ Weak-negative } & \multicolumn{2}{|c|}{ Weak-positive } \\
\hline Alien & Intruder & Ability & Melody & Abduction & Insect & Affection* & Jungle \\
\hline Assault & Invader & Abundance* & Miracle & Ambulance* & Knife & Avenue & King \\
\hline Bankrupt & Jail & Aid & Museum & Army & Lesbian* & Bible & Lantern \\
\hline Beggar & Loser & Ambition & Orchestra & Beast & Lie & Bouquet & Laughter \\
\hline Blackmail & Malaria & Angel & Orgasm* & Bomb & Madman & Breast & Lawsuit* \\
\hline Chaos & Misery & Bless & Palace & Bribe* & Massacre & Cabinet & Lightning* \\
\hline Cockroach & Mosquito & Blossom & Pancake & Bullet & Poison & Circus & Limber* \\
\hline Corpse & Mutation* & Breeze & Permission & Burglar & Quarrel & Costume & Lion \\
\hline Crap & Obesity & Castle & Plane & Casino* & Regret & Dawn* & Memory \\
\hline Debt & Obsession* & Church & Poetry & Cigar & Reptile* & Diver & Muffin \\
\hline Demon & Paralysis & Crown* & Pride & Cliff* & Robber & Dragon & News \\
\hline Execution & Pity & Democracy & Reunion & Cock* & Seasick & Drama & Nursery \\
\hline Fault & Poverty & Fantasy & Scholar & Crime & Sentiment* & Eagle & Owl \\
\hline Foul & Prison & Grace & Security & Excuse & Shotgun & Earth & Police \\
\hline Funeral & Scar & Ham & Silk & Fever & Snake & Essence & Prestige \\
\hline Gossip & Selfishness & Heritage & Soul & Fire* & Spider & Fame & Reality \\
\hline Grief & Sickness & History & Sweetheart & Germ & Storm & Father & Sailboat \\
\hline Guilt & Smallpox & Idol & Theory & Greed & Surgery* & Flight & Sex* \\
\hline Handicap & Theft & Jewel & Thumb & Hammer* & Tease & Fragrance* & Skyscraper \\
\hline Hatred & Toothache & Legend & Triumph & Hardship & Tobacco & Garment & Trumpet \\
\hline Hunger & Tumor & Liberty & Twilight & Hooker & Tornado & Hawk* & Virgin \\
\hline Ignorance & Vampire & Lightbulb & Valentine & Hurricane & Trash & Headlight & Waterfall \\
\hline Illness & Victim & Luxury & Virtue & Idiot & Volcano & Icebox & Wine \\
\hline Insult & War & Manner & Warmth & Infection & Weapon & Intercourse* & World \\
\hline
\end{tabular}

Target words with asterisk sign were eliminated, due to low accuracy $(<70 \%)$. 


\section{Appendix 3: ANOVA results in Experiment 1}

We performed 2 (valence) $\times 2$ (position) $\times 2$ (congruency proportion) mixed-factor ANOVAs for analyses on participant-level and item-level data. Valence was a within-participant/between-item variable, position was a within-participant/within-item variable, and congruency proportion was a between-participant/within-item variable. The following is the omnibus ANOVA table.
Results showed that the critical valence $\times$ position $\times$ congruency proportion interaction was significant in zRT and error rates in both participant and item analyses. Follow-up analyses showed that the valence $\times$ position interaction was significant when congruency proportion was high [participant: $F_{1}(1,94)=75.27, \mathrm{MSE}=0.06, p<0.01, \eta_{\mathrm{p}}{ }^{2}=0.45$ for zRTs and $F_{1}(1,94)=45.15, \mathrm{MSE}=56.19, p<0.01, \eta_{\mathrm{p}}{ }^{2}=0.32$ for error rates; item: $F_{2}(1,185)=114.61, \mathrm{MSE}=0.04$, $p<0.01, \eta_{\mathrm{p}}{ }^{2}=0.38$ for zRTs and $F_{2}(1,185)=82.71$, $\mathrm{MSE}=29.58, p<0.01, \eta_{\mathrm{p}}{ }^{2}=0.31$ for error rates], but not when it was equal [participant: $F_{1}(1,95)=0.06, \mathrm{MSE}=0.05$, $p=0.81, \eta_{\mathrm{p}}{ }^{2}=0.001$ for zRTs and $F_{1}(1,95)=0.24$, $\mathrm{MSE}=36.23, p=0.63, \eta_{\mathrm{p}}{ }^{2}=0.002$ for error rates; item: $F_{2}(1,185)=0.002, \mathrm{MSE}=0.04, p=0.97, \eta_{\mathrm{p}}{ }^{2}<0.001$ for zRTs and $F_{2}(1,185)=0.36, \mathrm{MSE}=28.80, p=0.55$, $\eta_{\mathrm{p}}{ }^{2}=0.002$ for error rates].

\begin{tabular}{|c|c|c|c|c|c|c|c|c|}
\hline \multirow{2}{*}{$\begin{array}{l}\text { Participant analyses } d f=(1,189) \\
\text { Source }\end{array}$} & \multicolumn{4}{|c|}{$z$ transformed RT } & \multicolumn{4}{|c|}{ Error rates } \\
\hline & MSE & $F$ & $p$ & $\eta_{\mathrm{p}}^{2}$ & MSE & $F$ & $p$ & $\eta_{\mathrm{p}}^{2}$ \\
\hline Position & 0.05 & 19.72 & $<0.01$ & 0.09 & 31.59 & 0.28 & 0.60 & $<0.01$ \\
\hline Valence & 0.06 & 1.76 & 0.19 & 0.01 & 46.75 & 2.49 & 0.12 & 0.01 \\
\hline Congruency proportion & 0.00 & 7.80 & 0.01 & 0.04 & 100.04 & 0.36 & 0.55 & $<0.01$ \\
\hline Position $\times$ valence & 0.05 & 38.24 & $<0.01$ & 0.17 & 46.16 & 24.52 & $<0.01$ & 0.11 \\
\hline $\begin{array}{l}\text { Position } \times \text { congruency Propor- } \\
\text { tion }\end{array}$ & 0.05 & 0.21 & 0.65 & $<0.01$ & 31.59 & 0.26 & 0.61 & $<0.01$ \\
\hline $\begin{array}{l}\text { Valence } \times \text { congruency Propor- } \\
\text { tion }\end{array}$ & 0.06 & 0.08 & 0.78 & $<0.01$ & 46.75 & 0.26 & 0.61 & $<0.01$ \\
\hline $\begin{array}{l}\text { Position } \times \text { valence } \times \text { congruency } \\
\text { proportion }\end{array}$ & 0.05 & 42.35 & $<0.01$ & 0.18 & 46.16 & 30.92 & $<0.01$ & 0.14 \\
\hline
\end{tabular}




\section{Appendix 4: ANOVA results in Experiment 2}

We performed 2 (valence) $\times 2$ (position) $\times 2$ (target eccentricity) repeated-measures ANOVA for analyses on participant-level data and mixed-factor ANOVA for analyses on item-level data. Valence was a between-item variable, while position and target eccentricity were within-item variables. The following is the omnibus ANOVA table.
Results showed that in both participant and item analyses in zRT the critical valence $\times$ position $\times$ target eccentricity interaction was not significant, whereas the valence $\times$ position interaction was significant, suggesting that. However, the three-way interaction was significant in error rates in both participant and item analyses. Follow-up analyses showed that the valence $\times$ position interaction was significant in far condition [participant: $F_{1}(1,191)=8.37, \mathrm{MSE}=13.07$, $p<0.01, \eta_{\mathrm{p}}{ }^{2}=0.04$; item: $F_{2}(1,188)=9.12, \mathrm{MSE}=5.93$, $p<0.01, \eta_{\mathrm{p}}{ }^{2}=0.05$ ], but not in near condition [participant: $F_{1}(1,191)=0.07, \mathrm{MSE}=12.03, p=0.80, \eta_{\mathrm{p}}{ }^{2}<0.001$; item: $\left.F_{2}(1,188)=0.05, \mathrm{MSE}=7.55, p=0.82, \eta_{\mathrm{p}}{ }^{2}<0.001\right]$.

\begin{tabular}{|c|c|c|c|c|c|c|c|c|}
\hline \multirow{2}{*}{$\begin{array}{l}\text { Participant analyses } d f=(1,191) \\
\text { Source }\end{array}$} & \multicolumn{4}{|c|}{ z-transformed RT } & \multicolumn{4}{|c|}{ Error rates } \\
\hline & $\overline{M S E}$ & $F$ & $p$ & $\eta_{\mathrm{p}}{ }^{2}$ & MSE & $F$ & $p$ & $\eta_{\mathrm{p}}{ }^{2}$ \\
\hline Position & 0.03 & 13.14 & $<0.01$ & 0.06 & 17.60 & 0.96 & 0.33 & $<0.01$ \\
\hline Valence & 0.06 & 5.16 & 0.02 & 0.03 & 41.94 & 3.37 & 0.07 & 0.02 \\
\hline Target eccentricity & 0.03 & 2.88 & 0.09 & 0.01 & 11.64 & 0.32 & 0.57 & $<0.01$ \\
\hline Position $\times$ valence & 0.02 & 10.12 & $<0.01$ & 0.05 & 14.06 & 3.25 & 0.07 & 0.02 \\
\hline Position $\times$ target eccentricity & 0.03 & 7.67 & $<0.01$ & 0.04 & 11.85 & 0.48 & 0.49 & $<0.01$ \\
\hline Valence $\times$ target eccentricity & 0.02 & 12.35 & $<0.01$ & 0.06 & 15.36 & 2.73 & 0.10 & 0.01 \\
\hline Position $\times$ valence $\times$ target eccentricity & 0.02 & 0.01 & 0.92 & $<0.01$ & 11.04 & 5.84 & 0.02 & 0.03 \\
\hline
\end{tabular}




\section{Appendix 5: ANOVA results in Experiment 3}

We performed a 2 (valence) $\times 2$ (position) $\times 2$ (valence strength) repeated-measures ANOVA for analyses on participant-level data and mixed-factor ANOVA for analyses on item-level data. Valence and valence strength were betweenitem variables and position was a within-item variable. The following is the omnibus ANOVA table.
Results showed that the critical valence $\times$ position $\times$ valence strength interaction was marginally significant in zRT in both participant and item analyses. Follow-up analyses showed that the valence $\times$ position interaction was significant when target's word valence was strong [participant: $F_{1}(1,182)=6.89$, MSE $=0.04, p<0.01, \eta_{\mathrm{p}}{ }^{2}=0.04 ;$ item: $F_{2}(1,89)=8.46$, $\left.\mathrm{MSE}=0.01, p=0.01, \eta_{\mathrm{p}}{ }^{2}=0.09\right]$, but not when it was weak [participant: $F_{1}(1,182)=0.17, \mathrm{MSE}=0.07, p=0.68, \eta_{\mathrm{p}}^{2}=0.001$; item: $\left.F_{2}(1,74)=0.02, \mathrm{MSE}=0.01, p=0.88, \eta_{\mathrm{p}}{ }^{2}<0.001\right]$.

\begin{tabular}{|c|c|c|c|c|c|c|c|c|}
\hline \multirow{2}{*}{$\begin{array}{l}\text { Participant analyses } d f=(1,182) \\
\text { Source }\end{array}$} & \multicolumn{4}{|c|}{ z-transformed RT } & \multicolumn{4}{|c|}{ Error rates } \\
\hline & MSE & $F$ & $p$ & $\eta_{\mathrm{p}}^{2}$ & MSE & $F$ & $p$ & $\eta_{\mathrm{p}}^{2}$ \\
\hline Position & 0.09 & 0.42 & 0.52 & $<0.01$ & 193.09 & 2.58 & 0.11 & 0.01 \\
\hline Valence & 0.08 & 8.98 & $<0.01$ & 0.05 & 43.98 & 2.30 & 0.13 & 0.01 \\
\hline Valence strength & 0.06 & 134.40 & $<0.01$ & 0.42 & 44.88 & 138.74 & $<0.01$ & 0.43 \\
\hline Position $\times$ valence & 0.05 & 1.83 & 0.18 & 0.01 & 54.77 & 4.87 & 0.03 & 0.03 \\
\hline Position $\times$ valence strength & 0.06 & 0.04 & 0.85 & $<0.01$ & 51.24 & 2.27 & 0.13 & 0.01 \\
\hline Valence $\times$ valence strength & 0.06 & 22.05 & $<0.01$ & 0.11 & 59.32 & 5.36 & 0.02 & 0.03 \\
\hline Position $\times$ valence $\times$ valence strength & 0.06 & 3.23 & 0.07 & 0.02 & 66.78 & 0.70 & 0.40 & $<0.01$ \\
\hline
\end{tabular}




\section{Appendix 6: ANOVA results in Experiment 1's follow-up experiment}

The design and procedure of this follow-up study were identical to Experiment 1's equal congruency proportion condition except that 192 participants were recruited, the number of observation was 96 per condition and the instruction did not state any information about congruency and the proportion of congruent and incongruent trials. (See the General Discussion section for the rationale of this follow-up experiment.) We performed 2 (valence) $\times 2$ (position) repeatedmeasures ANOVA for analyses on participant-level data and mixed-factor ANOVA for analyses on item-level data. Valence was a between-item variable.
Results showed that the valence $\times$ position interaction was significant in zRT in both participant and item analyses and in error rates in item analyses.

\begin{tabular}{|c|c|c|c|c|c|c|c|c|}
\hline \multirow{2}{*}{$\begin{array}{l}\text { Participant analyses } \\
d f=(1,190) \\
\text { Source }\end{array}$} & \multicolumn{4}{|c|}{ z-transformed RT } & \multicolumn{4}{|c|}{ Error rates } \\
\hline & MSE & $F$ & $p$ & $\eta_{\mathrm{p}}^{2}$ & MSE & $F$ & $p$ & $\eta_{\mathrm{p}}^{2}$ \\
\hline Position & 0.02 & 27.17 & $<0.01$ & 0.13 & 10.27 & 0.06 & 0.80 & $<0.01$ \\
\hline Valence & 0.05 & 0.51 & 0.48 & $<0.01$ & 22.06 & 1.92 & 0.17 & 0.01 \\
\hline Position $\times$ valence & 0.03 & 8.24 & $<0.01$ & 0.04 & 16.87 & 3.36 & 0.07 & 0.02 \\
\hline
\end{tabular}

\section{References}

Anwyl-Irvine, A. L., Dalmaijer, E. S., Hodges, N., \& Evershed, J. (2020). Online timing accuracy and precision: A comparison of platforms, browsers, and participant's devices. https://doi. org/10.31234/osf.io/jfeca

Bates, D., Maechler, M., Bolker, B., \& Walker, S. (2015). Fitting linear mixed-effects models using lme4. Journal of Statistical Software, 67, 1-48. R package (Version 1.1-12). https://cran.r-project.org/ web/packages/lme4/index.html. https://doi.org/10.18637/jss.v067. i01

Boroditsky, L. (2000). Metaphoric structuring: Understanding time through spatial metaphors. Cognition, 75, 1-28. https://doi. org/10.1016/S0010-0277(99)00073-6.

Botvinick, M. M., Braver, T. S., Barch, D. M., Carter, C. S., \& Cohen, J. D. (2001). Conflict monitoring and cognitive control. Psychological Review, 108, 624-652. https://doi. org/10.1037/0033-295x.108.3.624

Bradley, M.M., \& Lang, P.J. (1999). Affective norms for English words (ANEW): Stimuli, instruction manual and affective ratings. Technical report $C$-1. Gainesville, FL: The Center for Research in Psychophysiology, University of Florida.

Bridges, D., Pitiot, A., MacAskill, M. R., \& Peirce, J. W. (2020). The timing mega-study: Comparing a range of experiment generators, both lab-based and online. PeerJ. https://doi.org/10.31234 /osf.io/d6nu5.

Bugg, J. M., Jacoby, L. L., \& Toth, J. P. (2008). Multiple levels of control in the Stroop task. Memory and Cognition, 36, 1484-1494. https://doi.org/10.3758/MC.36.8.1484.

Casasanto, D. (2008). Similarity and proximity: When does close in space mean close in mind? Memory and Cognition, 36, 10471056. https://doi.org/10.3758/MC.36.6.1047.

Casasanto, D., \& Gijssels, T. (2015). What makes a metaphor an embodied metaphor? Linguistics Vanguard, 1, 327-337. https:// doi.org/10.1515/lingvan-2014-1015.
Clark, H. H., \& Brownell, H. H. (1975). Judging up and down. Journal of Experimental Psychology Human Perception and Performance, 1, 339-352. https://doi.org/10.1037/0096-1523.1.4.339.

Clark, H. H., \& Chase, W. G. (1974). Perceptual coding strategies in formation and verification of descriptions. Memory and Cognition, 2, 101-111. https://doi.org/10.3758/BF03197499.

Cohen, J. (1988). Statistical power analysis for the behavioral sciences (2nd ed.). Hillsdale: Lawrence Erlbaum.

Collins, A. M., \& Loftus, E. F. (1975). A spreading-activation theory of semantic processing. Psychological Review, 82, 407-428. https ://doi.org/10.1037/0033-295X.82.6.407.

Crawford, L. E., Margolies, S. M., Drake, J. T., \& Murphy, M. E. (2006). Affect biases memory of location: Evidence for the spatial representation of affect. Cognition and Emotion, 20, 1153-1169. https://doi.org/10.1080/02699930500347794.

de La Vega, I., de Filippis, M. N., Lachmair, M., Dudschig, C., \& Kaup, B. (2012). Emotional valence and physical space: Limits of interaction. Journal of Experimental Psychology: Human Perception and Performance, 38, 375-385. https://doi.org/10.1037/a0024979.

de Wit, B., \& Kinoshita, S. (2015). RT distribution analysis of relatedness proportion effects in lexical decision and semantic categorization reveals different mechanisms. Memory and Cognition, 43, 99-110. https://doi.org/10.3758/s13421-014-0446-6.

Dudschig, C., de la Vega, I., \& Kaup, B. (2014). Embodiment and second-language: Automatic activation of motor responses during processing spatially associated L2 words and emotion L2 words in a vertical Stroop paradigm. Brain and Language, 132, 14-21. https://doi.org/10.1016/j.bandl.2014.02.002.

Dudschig, C., de la Vega, I., \& Kaup, B. (2015). What's up? Emotionspecific activation of vertical space during language processing. Acta Psychologica, 156, 143-155. https://doi.org/10.1016/j.actps y.2014.09.015.

Faust, M. E., Balota, D. A., Ferraro, F. R., \& Spieler, D. H. (1999). Individual differences in information processing rate and amount: Implications for group differences in response 
latency. Psychological Bulletin, 125, 777-799. https://doi. org/10.1037/0033-2909.125.6.777.

Flumini, A., \& Santiago, J. (2013). Time (also) flies from left to right... if it is needed! In M. Knauff, M. Pauen, N. Sebanz, \& I. Wachmuz (Eds.), Proceedings of the 36th Annual Conference of the Cognitive Science Society (pp. 2315-2320). Austin, TX: Cognitive Science Society.

Gallant, J. (2020). Co-activation in the bilingual lexicon: Evidence from Chinese-English bilinguals. (Master's thesis, Brock University, St. Catharines, Ontario, Canada). https://dr.library.brocku.ca/ handle/10464/14760.

Gozli, D. G., Chow, A., Chasteen, A. L., \& Pratt, J. (2013). Valence and vertical space: Saccade trajectory deviations reveal metaphorical spatial activation. Visual Cognition, 21, 628-646. https://doi. org/10.1080/13506285.2013.815680.

Huang, Y., Tse, C.-S., \& Cho, K. W. (2014). Living in the north is not necessarily favorable: Different metaphoric associations between cardinal direction and valence in Hong Kong and in the United States. European Journal of Social Psychology, 44, 360-369. https://doi.org/10.1002/ejsp.2013.

Huang, Y., \& Tse, C.-S. (2015). Re-examining the automaticity and bidirectionality of the activation of the spatial-valence "good is up" metaphoric association. PLoS One, 10(4), e0123371. https:// doi.org/10.1371/journal.pone.0123371.

Huang, Y., Tse, C.-S., \& Xie, J. (2018). The bidirectional congruency effect of brightness-valence metaphoric association in the Strooplike and priming paradigms. Acta Psychologica, 189, 76-92. https ://doi.org/10.1016/j.actpsy.2017.10.006.

Hutchison, K. A. (2007). Attentional control and the relatedness proportion effect in semantic priming. Journal of Experimental Psychology: Learning, Memory, and Cognition, 33, 645-662. https ://doi.org/10.1037/0278-7393.33.4.645.

Judd, C. M., Westfall, J., \& Kenny, D. A. (2012). Treating stimuli as a random factor in social psychology: A new and comprehensive solution to a pervasive but largely ignored problem. Journal of Personality and Social Psychology, 103, 54-69. https://doi. org/10.1037/a0028347.

Keefer, L. A., Landau, M. J., Sullivan, D., \& Rothschild, Z. K. (2011). Exploring metaphor's epistemic function: Uncertainty moderates metaphor-consistent priming effects on social perceptions. Journal of Experimental Social Psychology, 47, 657-660. https://doi.org/10.1016/j.jesp.2011.02.002.

Keefer, L. A., Landau, M. J., Sullivan, D., \& Rothschild, Z. K. (2014). Embodied metaphor and abstract problem solving: Testing a metaphoric fit hypothesis in the health domain. Journal of Experimental Social Psychology, 55, 12-20. https://doi. org/10.1016/j.jesp.2014.05.012.

Klein, R. A., Vianello, M., Hasselman, F., Adams, B. G., Adams, R. B., Alper, S., et al. (2018). Many Labs 2: Investigating variation in replicability across samples and settings. Advances in Methods and Practices in Psychological Science, 1, 443-490. https://doi.org/10.1177/2515245918810225.

Kruglanski, A. W. (1989). Lay epistemics and human knowledge: Cognitive and motivational bases. New York: Springer.

Kuznetsova, A., Brockhoff, P. B., \& Christensen, R. H. B. (2016). lmerTest: Tests for random and fixed effects for linear mixed effect models (lmer objects of lme 4 package). R package version 2.0-29. https://cran.r-project.org/web/packages/lmerTest/.

Lakens, D. (2011). High skies and oceans deep: Polarity benefits or mental simulation? Frontiers in Psychology, 2, 21. https://doi. org/10.3389/fpsyg.2011.00021.

Lakens, D. (2012). Polarity correspondence in metaphor congruency effects: Structural overlap predicts categorization times for bipolar concepts presented in vertical space. Journal of Experimental Psychology: Learning Memory and Cognition, 38, 726-736. https://doi.org/10.1037/a0024955.
Lakens, D. (2013). Calculating and reporting effect sizes to facilitate cumulative science: A practical primer for $\mathrm{t}$ tests and ANOVAs. Frontiers in Psychology, 4, 863. https://doi.org/10.3389/fpsyg .2013.00863.

Lakoff, G. (2008). The neural theory of metaphor. In R. W. Gibbs (Ed.), Cambridge handbook of metaphor and thought (pp. 17-38). Cambridge: Cambridge University Press.

Lakoff, G. (2012). Explaining embodied cognition results. Topics in Cognitive Science, 4, 773-785. https://doi.org/10.111 $1 / \mathrm{j} .1756-8765.2012 .01222 . x$.

Lakoff, G., \& Johnson, M. (1980). Metaphors we live by. Chicago: University of Chicago Press. https://doi.org/10.7208/chica go/9780226470993.001.0001.

Lakoff, G., \& Johnson, M. (1999). Philosophy in the flesh: The embodied mind and its challenge to western thought. Chicago: University of Chicago Press. https://doi.org/10.1590/S0102 -44502001000100008 .

Landau, M. J., Keefer, L. A., \& Rothschild, Z. K. (2014). Epistemic motives moderate the effect of metaphoric framing on attitudes. Journal of Experimental Social Psychology, 53, 125-138. https ://doi.org/10.1016/j.jesp.2014.03.009.

Landau, M. J., Meier, B. P., \& Keefer, L. A. (2010). A metaphorenriched social cognition. Psychological Bulletin, 136, 10451067. https://doi.org/10.1037/a0020970.

Landau, M. J., Nelson, N. M., \& Keefer, L. A. (2015). Divergent effects of metaphoric company logos: Do they convey what the company does or what I need? Metaphor and Symbol, 30, 314-338. https://doi.org/10.1080/10926488.2015.1074806.

Lebois, L. A., Wilson-Mendenhall, C. D., \& Barsalou, L. W. (2015). Are automatic conceptual cores the gold standard of semantic processing? The context-dependence of spatial meaning in grounded congruency effects. Cognitive Science, 39, 17641801. https://doi.org/10.1111/cogs.12174.

Lim, R. Y.-H., Yap, M. J., \& Tse, C.-S. (2020). Individual differences in Cantonese Chinese word recognition: Insights from the Chinese Lexicon Project. Quarterly Journal of Experimental Psychology, 73, 504-518. https://doi.org/10.1177/1747021820906566.

Lynott, D., \& Coventry, K. (2014). On the ups and downs of emotion: Testing between conceptual-metaphor and polarity accounts of emotional valence-spatial location interactions. Psychonomic Bulletin and Review, 21, 218-226. https://doi.org/10.3758/s1342 3-013-0481-5.

Mandler, J. M. (1992). How to build a baby: II Conceptual primitives. Psychological Review, 99, 587-604. https://doi. org/10.1037/0033-295X.99.4.587.

Meier, B. P., Fetterman, A. K., \& Robinson, M. D. (2015). Black and white as valence cues: A large scale replication effort of Meier, Robinson, and Clore (2004). Social Psychology, 46, 174-178. https://doi.org/10.1027/1864-9335/a000236.

Meier, B. P., \& Robinson, M. D. (2004). Why the sunny side is up: Associations between affect and vertical position. Psychological Science, 15, 243-247. https://doi.org/10.111 1/j.0956-7976.2004.00659.x.

Meier, B. P., Robinson, M. D., \& Clore, G. L. (2004). Why good guys wear white: Automatic inferences about stimulus valence based on brightness. Psychological Science, 15, 82-87. https://doi.org/ 10.1111/j.0963-7214.2004.01502002.x.

Meier, B. P., Schnall, S., Schwarz, N., \& Bargh, J. A. (2012). Embodiment in social psychology. Topics in Cognitive Science, 4, 705716. https://doi.org/10.1111/j.1756-8765.2012.01212.x.

Neely, J. H. (1991). Semantic priming effects in visual word recognition: A selective review of current findings and theories. In D. Besner \& G. W. Humphreys (Eds.), Basic processes in reading: Visual word recognition (pp. 264-336). Hillsdale: Lawrence Erlbaum Associates. https://doi.org/10.4324/9780203052242-12. 
Neely, J. H., \& Keefe, D. E. (1989). Semantic context effects on visual word processing: A hybrid prospective/retrospective processing theory. In G. H. Bower (Ed.), The psychology of learning and motivation: Advances in research and theory (24th ed., pp. 207-248). New York: Academic Press. https://doi.org/10.1016/ S0079-7421(08)60538-1.

Neely, J. H., Keefe, D. E., \& Ross, K. L. (1989). Semantic priming in the lexical decision task: Roles of prospective prime-generated expectancies and retrospective semantic matching. Journal of Experimental Psychology: Learning, Memory, and Cognition, 15, 1003-1019. https://doi.org/10.1037/0278-7393.15.6.1003.

Oosterwijk, S., Rotteveel, M., Fischer, A. H., \& Hess, U. (2009). Embodied emotion concepts: How generating words about pride and disappointment influences posture. European Journal of Social Psychology, 39, 457-466. https://doi.org/10.1002/ejsp.584.

Palma, T. A., Garrido, M. V., \& Semin, G. R. (2011). Grounding person memory in space: Does spatial anchoring of behaviors improve recall? European Journal of Social Psychology, 41, 275-280. https://doi.org/10.1002/ejsp.795.

Palma, T. A., Garrido, M. V., \& Semin, G. R. (2014). Situating person memory: The role of the visual context on memory for behavioral information. Journal of Experimental Social Psychology, 52, 32-43. https://doi.org/10.1016/j.jesp.2013.12.006.

Peirce, J. W., Gray, J. R., Simpson, S., MacAskill, M. R., Höchenberger, R., Sogo, H., et al. (2019). PsychoPy2: Experiments in behavior made easy. Behavior Research Methods, 51, 195-203. https://doi.org/10.3758/s13428-018-01193-y.

Posner, M. I., \& Snyder, C. R. R. (1975). Facilitation and inhibition in the processing of signals. In P. M. A. Rabbitt \& S. Dornic (Eds.), Attention and Performance V (pp. 669-682). New York: Academic Press.

Potthoff, J., La Face, A., \& Schienle, A. (2020). The color nutrition information paradox: Effects of suggested sugar content on food cue reactivity in healthy young women. Nutrients, 12,312 . https ://doi.org/10.3390/nu12020312.

Proctor, R. W., \& Cho, Y. S. (2006). Polarity correspondence: A general principle for performance of speeded binary classification tasks. Psychological Bulletin, 132, 416-442. https://doi. org/10.1037/0033-2909.132.3.416.

Santiago, J., Ouellet, M., Román, A., \& Valenzuela, J. (2012). Attentional factors in conceptual congruency. Cognitive Science, 36, 1051-1077. https://doi.org/10.1111/j.1551-6709.2012.01240.x.

Santiago, J., Román, A., \& Ouellet, M. (2011). Flexible foundations of abstract thought: A review and a theory. In A. Maass \& T.
Schubert (Eds.), Spatial Dimensions of Social Thought (pp. 39-108). Berlin: de Gruyter.

Tolaas, J. (1991). Notes on the origin of some spatialization metaphors. Metaphor and Symbolic Activity, 6, 203-218. https://doi. org/10.1207/s15327868ms0603_4.

Tracy, J. L., \& Matsumoto, D. (2008). The spontaneous expression of pride and shame: Evidence for biologically innate nonverbal displays. Proceedings of the National Academy of Sciences, 105, 11655-11660. https://doi.org/10.1073/pnas.0802686105.

Tse, C.-S., Balota, D. A., Yap, M. J., Duchek, J. M., \& McCabe, D. P. (2010). Effects of healthy aging and early-stage dementia of the Alzheimer's type on components of response time distributions in three attention tasks. Neuropsychology, 24, 300-315. https:// doi.org/10.1037/a0018274.

Tse, C.-S., Hutchison, K. A., \& Li, Y. (2011). Effects of contextual similarity and target-repetition proportion on negative priming in RT distributional analyses. Journal of Experimental Psychology: Human Perception and Performance, 37, 180-192. https://doi. org/10.1037/a0019930.

Voss, A., Rothermund, K., Gast, A., \& Wentura, D. (2013). Cognitive processes in categorical and associative priming: A diffusion model analysis. Journal of Experimental Psychology: General, 142, 536-559. https://doi.org/10.1037/a0029459.

Voss, A., Voss, J., \& Lerche, V. (2015). Assessing cognitive processes with diffusion model analyses: A tutorial based on fast-dm-30. Frontiers in Psychology, 6, 336. https://doi.org/10.3389/fpsyg .2015.00336.

Wapner, S., Werner, H., \& Krus, D. M. (1957). The effect of success and failure on space localization. Journal of Personality, 25, 752-756. https://doi.org/10.1111/j.1467-6494.1957.tb01563.x.

Weger, U. W., Meier, B. P., Robinson, M. D., \& Inhoff, A. W. (2007). Things are sounding up: Affective influences on auditory tone perception. Psychonomic Bulletin and Review, 14, 517-521. https ://doi.org/10.3758/BF03194100.

Williams, L. E., Huang, J. Y., \& Bargh, J. A. (2009). The scaffolded mind: Higher mental processes are grounded in early experience of the physical world. European Journal of Social Psychology, 39, 1257-1267. https://doi.org/10.1002/ejsp.665.

Publisher's Note Springer Nature remains neutral with regard to jurisdictional claims in published maps and institutional affiliations. 